Sriraj Gokarakonda, Christoph van Treeck, Rajan Rawal

\title{
Influence of building design and control parameters on the potential of mixed-mode buildings in India
}

Originally published in:

Building and Environment, 148 (2019) 157-172

DOI: 10.1016/j.buildenv.2018.10.043 
Sriraj Gokarakonda a, *

Christoph van Treeck $b$

Rajan Rawal c

\section{Influence of building design and control parameters on the potential of mixed-mode buildings in India}

a Wuppertal Institut für Klima, Umwelt, Energie gGmbH, Wuppertal, Germany

b Institute of Energy Efficiency and Sustainable Building, RWTH Aachen University, Aachen, Germany

c Centre for Advanced Research in Building Science and Energy (CARBSE), CEPT University, Ahmedabad, India

* Corresponding author:

Sriraj Gokarakonda

Wuppertal Institut

Döppersberg 19

42349 Wuppertal

Germany

E-mail: sriraj.gokarakonda@wupperinst.org

Phone: +49 202 2492-155

Fax: +49 202 2492-250

This is the author's version of a work that was accepted for publication. Changes resulting from the publishing process, such as editing, corrections and structural formatting, may not be reflected in this document. Changes may have been made to this work since it was submitted for publication. A definitive version was subsequently published in the Journal cited above. 


\section{Abstract}

The potential of mixed-mode office buildings with varying design and control parameters is examined by using an uncertainty analysis in the three climate zones of India. The analysis is in terms of cooling energy consumption, thermal comfort conditions, and natural ventilation hours. Furthermore, influential parameters are identified using sensitivity analysis. In this study, opening the windows enables natural ventilation. Night-time ventilation through the windows is not enabled because these are mostly closed at night. A maximum natural ventilation of $10 \%$ of the total building occupancy hours are observed in warm and humid, and hot and dry climates; however, they are slightly higher in the composite climate. A further increase in the number of natural ventilation hours leads to an increase in the occupancy hours outside the Indian Model for Adaptive Comfort model for mixed-mode buildings with at least $90 \%$ of occupants are satisfied. There are no occupancy hours outside of $80 \%$ of occupants are satisfied. The choice of thermal comfort band is crucial for determining the potential of mixed-mode buildings. The cooling setpoint temperature, building size, window solar heat gain coefficient, and surface properties of exterior surfaces are identified as the more influential parameters than the thermophysical properties of building envelope constructions. Although the building envelope which is in compliance with the Energy Efficient Building Code of India increases energy efficiency during air-conditioning periods, whether it reduces natural ventilation hours, because of overheating during such period remains to be determined.

Keywords: mixed-mode buildings; hybrid ventilation; uncertainty analysis; sensitivity analysis; Energy Efficient Building Code of India (ECBC); Indian Model for Adaptive Thermal Comfort;

\section{Introduction}

The energy consumption of commercial buildings in India has been consistently increasing in previous years. In 2015-2016, they used approximately 9\% of the total electricity consumption of the country [1]. In typical commercial buildings in India, space cooling consumes approximately half of the total electrical energy [2]. Furthermore, as the service and construction sectors rapidly grow, space cooling presents a huge potential for energy 
saving $[3,4]$. Conventional and alternative low-energy space technologies and energy efficient buildings are essential for reducing space cooling energy consumption. The Standards and Labelling programme of the Bureau of Energy Efficiency has been successful in accelerating the energy efficiency and uptake of conventional space cooling technologies, such as direct expansion systems. On the other hand, alternative technologies, including combined heating, cooling and power, and concentrated solar power satisfy an insignificant percentage of the space cooling energy demand [5-7,4]. Accordingly, the Energy Efficient Building Code $(\mathrm{ECBC})$ is perceived as a crucial policy instrument for designing energy efficient buildings [8-12]. Furthermore, space cooling energy consumption can be further minimised through mixed-mode buildings.

Mixed-mode buildings are a bridge between buildings that are completely and continuously i.e., fully air-conditioned and fully naturally ventilated buildings. Broadly, they are classified as zoned and complementary based on where and when air conditioning is used. In the former, the use of air conditioning is restricted to a few areas of the building; in the latter, its use is periodic [13-15]. Mixed-mode buildings signify an approach of 'sufficiency' instead of 'efficiency' for reducing energy consumption, i.e., maintaining thermal comfort conditions by minimising the area and operating hours of air conditioning [16-20].

Conceptually, mixed-mode buildings indicate optimal design and control of passive and active space cooling strategies rather than presenting specific technical solutions [13]. Passive strategies are based on climate and design parameters, such as building size and geometry, envelope, internal mass, and internal heat gains; these mostly rely on natural ventilation for providing thermal comfort conditions [21-23]. On the other hand, active strategies use conventional mechanical heating ventilation and air-conditioning (HVAC) systems, such as constant or variable air volume systems and thermally activated building systems [20,24]. Moreover, novel low-energy and renewable HVAC systems, including 
thermal storage systems with phase-change materials [25], hybrid air conditioner [26], natural air-conditioning wall [27], and on-site thermal energy generation and storage [28] are also used. Furthermore, the optimum control of these strategies ensures the satisfactory operation of mixed-mode buildings. A simple and frequently used mixed-mode control is a manually operated window, whereas building energy management systems are used for sophisticated control and operation $[29,15,30,20]$.

\subsection{Mixed-mode buildings in India}

The empirical evidence, although limited, suggests that most small to medium office buildings in India are built as zoned and operate as complementary mixed-mode buildings [31,32]. On-field research findings from office buildings with day time occupancy show that air conditioners operate only during the day and only peak during summer; they are not used at night and during the off-peak season. Furthermore, it was observed that opening windows manually is a popular mixed-mode control strategy to maintain thermal comfort conditions; a fan is also used for local air movement $[19,33]$. The HVAC system sales data suggest that most new and existing small to medium office buildings use room air-conditioners sans mechanical ventilation systems [34,35]. Mixed-mode buildings in India are not designed as mixed-mode buildings, but are built and operated that way for various reasons, such as cost, comfort, and prestige. They are virtually omnipresent. Pragmatically, the majority of mixedmode buildings with day time occupancy in India are characterised by room air conditioners and windows that can be opened; hereon, these buildings are referred to as 'Indian mixedmode buildings (IMMBs)'. Furthermore, when IMMBs are unoccupied, opening windows at night as a ventilation strategy is impractical. 


\subsection{Challenges and research gaps}

Energy efficient buildings in India are often designed as naturally ventilated, zoned, and complementary mixed-mode buildings [36-43]. However, they are often designed by energyconscious architects as exemplar projects and are not replicated in the mass market $[44,45]$. Therefore, the ECBC is implemented for reducing energy consumption in commercial buildings. The ECBC is mandatory for buildings with a minimum connected load of $100 \mathrm{~kW}$. Its provision increases the efficiency of building envelope and electro-mechanical systems [12]. When compared with conventional buildings, the ECBC-compliant buildings would achieve a minimum of $25 \%$ energy savings. Beyond the minimum, higher energy efficiency levels, called ECBC+ and SuperECBC-compliant buildings would achieve energy savings of 35 and 50\%, respectively [11]. The ECBC defines mixed-mode as a 'building in which natural ventilation is employed as the primary mode of ventilating the building and airconditioning is deployed as and when required' [12]. To enable mixed-mode operations and achieve resultant energy savings, the code recommends an economiser in mechanical ventilation systems [46].

Evidently, mixed-mode buildings have a potential application in Indian climates [47,48,24,49]. Moreover, building design parameters, such as climate and micro-climate [50], building size and geometry [51-53], building envelope and construction [51,54-56], internal mass [57-59], internal heat gains [60,61], and control parameters for mixed-mode operations $[29,15,62,63]$ determine the potential of mixed-mode buildings. A few of these are also outside the purview of the ECBC. Several specific inputs for each of these parameters (see 2.4 Input parameters) are important for maximising hours of natural ventilation. However, most of the existing studies on mixed-mode buildings use mechanical ventilation systems and deploy night ventilation strategies, which are considerably uncommon in IMMBs. Therefore, 
IMMBs operate as fully air-conditioned buildings during the air-conditioning mode and as fully naturally ventilated buildings during the natural ventilation mode.

Moreover, mixed-mode buildings cannot be simply considered as fully airconditioned buildings with openable windows [15]. For example, as per the ECBC, the maximum assembly U-values of the external wall for office buildings in hot climates are 0.4 , 0.34, and $0.22 \mathrm{~W} /\left(\mathrm{m}^{2} \mathrm{~K}\right)$ for the $\mathrm{ECBC}, \mathrm{ECBC}+$, and superECBC-compliant buildings, respectively. Typically, these U-values can only be achieved by applying thermal insulation to external walls. However, this may cause overheating during naturally ventilated periods, leading to thermal discomfort $[64,56]$. The potential of mixed-mode buildings is determined by their ability to minimise energy consumption during the air-conditioning period, maximise the period of natural ventilation, and provide thermal comfort during both operating modes. However, as illustrated, design strategies in both modes may also be contradictory.

\subsection{Objectives of the study}

The total floor area of office buildings in India with minimum connected loads of $100 \mathrm{~kW}$ (thus requiring them to be compliant with the ECBC) is unclear. Furthermore, the use of economisers is considerably uncommon. The IMMBs represent most existing and newly constructed buildings. There is a general lack of consensus among building professionals concerning the effect of ECBC on IMMBs. In addition, there are persistent research gaps regarding the potential of IMMBs and the most influential design and control parameters that affect such potential. Therefore, this study investigates the influence of building design and control parameters on the potential of IMMBs. Furthermore, this study identifies pertinent research gaps in their design. This helps in optimising important design and control parameters for increasing the IMMB potential. 


\section{Methodology}

The specific inputs for various building design and control parameters are usually diverse and accept a range of input values. The output results of interest in the study are probabilistic (potential) and ranking (influence) in nature. Furthermore, this study aims to identify research gaps in modelling IMMBs. Therefore, this study used a large-scale modelling approach by applying uncertainty analysis (UA) and sensitivity analysis (SA) to building performance simulation (BPS) inputs and outputs. In the following sections, the methods for modelling mixed-mode buildings, conducting UA and SA, organising workflow, and inputs and outputs are discussed.

\subsection{Modelling mixed-mode buildings}

The modelling of natural ventilation and coupled heat and mass transfer, and the choice and modelling of thermal comfort conditions are crucial for modelling mixed-mode buildings [65]. For modelling natural ventilation, extrapolating weather data from meteorological stations to suit site-specific conditions and generating accurate wind pressure coefficients are crucial $[66,67]$. For modelling coupled heat and mass transfer, the accurate calculation of surface convection heat transfer coefficient is crucial. It is sensitive to several parameters in the space, including turbulent and unsteady airflow patterns arising from natural ventilation and the use of ceiling fans (such as the case in IMMBs), [68]. For modelling mixed-mode buildings, the BPS tools are coupled with multizone networks or computational fluid dynamics models, depending on the required accuracy of results [69-71].

For conducting the BPS, EnergyPlus (V8.8) is used in the present study. It uses an airflow network model developed by Walton [72] and calculates wind pressure coefficients based on a model by Swami \& Chandra [73]. For ensuring accuracy, the building design and control parameters are kept within the acceptable modelling protocol and sensitivities of the 
EnergyPlus airflow network model; it models natural ventilation, coupled heat and mass transfer, and mixed-mode controls [74].

For modelling thermal comfort conditions, adaptive thermal comfort (ATC) models are recently gaining validity for their suitability and application in naturally ventilated and mixed-mode buildings [18]. For the present study, the Indian Model for Adaptive Comfort (IMAC), which is an ATC that is recommended by the ECBC, is chosen as the thermal comfort model for mixed-mode buildings [12]. The general governing equation for the ATC models is as follows:

$$
T_{n}=x *(y)+z
$$

In the IMAC model for mixed-mode buildings, $T_{n}$ is the indoor neutral operative temperature $\left({ }^{\circ} \mathrm{C}\right)$; the value of $x$ is $0.28 ; y$ is the 30 -d outdoor running mean air temperature valid for a $13-38.5^{\circ} \mathrm{C}$ range; the value of $z$ is 17.87 . The IMAC has three categories of acceptability bands - 90,85 , and $80 \%$ of occupants are, satisfied. The indoor operative temperature, $T_{o}$, should be within $T_{n} \pm \varepsilon$, where $\varepsilon$ assumes the values of $3.5,4.8$, and $5.9{ }^{\circ} \mathrm{C}$ for the 90,85 , and $80 \%$ bands, respectively [33]. The ATC models assume behavioural adaptations to the environment through actions, such as opening the windows, turning on the fans, and wearing appropriate clothing. Hence, clothing insulation (clo), metabolic activity (met), air speed etc. are implicit in the ATC models. Therefore, the ATC models are extremely sensitive to $T_{o}$, which is given by the following [75]:

$$
T_{o}=W T_{a}+(1-W) T_{m r t}
$$

where

$T_{m r t}=$ mean radiant temperature $\left({ }^{\circ} \mathrm{C}\right)$,

$T_{a}=$ air temperature $\left({ }^{\circ} \mathrm{C}\right)$, and

$\mathrm{W}$ is the weighting coefficient, which depends on the surface heat transfer from the human body. It is given by the following equation [75]: 


$$
W=\frac{h_{c}}{h_{c}+h_{r}}
$$

where

$h_{r}=$ linear radiant heat transfer coefficient at the outer surface of a clothed body $\left(\mathrm{W} /\left(\mathrm{m}^{2} \mathrm{~K}\right)\right)$

$h_{c}=$ convective heat transfer coefficient at the outer surface of a clothed body $\left(\mathrm{W} /\left(\mathrm{m}^{2} \mathrm{~K}\right)\right)$

Problems that arise because of behavioural adaptations in the space, such as turbulent and unsteady airflow caused by ceiling fans, may result in dynamic convection coefficients and mixed-mode control modelling (window opening) are limitations of the study These are the limitations of the study and areas where further research is needed, as explained below.

In the present study, the thermal analysis research program (TARP) algorithm has been used for calculating internal convection coefficient. It does not account for changes in the convection coefficient because of changes in the indoor air velocity [76]. Furthermore, $W$ increases as air speed increases in the space. Because the linearised radiant heat transfer coefficient $\left(h_{r}\right)$ is typically constant, an increase in the air velocity results in higher values of the convective heat transfer coefficient $\left(h_{c}\right)$. However, EnergyPlus calculates $T_{n}$ as the average of $T_{m r t}$ and $T_{a}$. Although this is a valid assumption for air velocities lower than 0.2 $\mathrm{m} / \mathrm{s}$, air velocities in spaces with natural ventilation and ceiling fan operation are usually considerably higher than $0.2 \mathrm{~m} / \mathrm{s}$ [77-79]. The IMAC provides the seasonal variations in clo values and indoor-air speeds for mixed-mode buildings [33]. The BPS models should incorporate such appropriate behavioural adaptations and heat transfer models into the schedules and values for clo, met, and air velocity that are commensurate with the ATC model. However, because this a comparative parametric study, these limitations do not affect the results, which are still sufficient to satisfy the objectives of the study.

Multiple factors affect behaviour of occupants in opening windows, such as indoor and outdoor weather conditions, ventilation, periodic events, intervals and occupancy, 
seasonal and long-term behaviour patterns, lighting, energy, security, noise, ambient air quality, design, and other social and functional problems [80-83]. Broadly, the window control models for the BPS applications can be classified as either models based on temperature only or strategies based on temperature and other factors $[84,85]$. The windowopening behaviour is deterministic for calculating the potential of mixed-mode buildings. However, existing studies on window-opening models are performed in temperate and cold climate zones that are members of the Organisation for Economic Co-operation and Development. Realistic conclusions cannot be drawn from these models and limited studies exist in the Indian context $[19,78]$. Considering the stochastic nature of opening windows, Borgeson \& Brager [80] suggest the use of simple and first-hand reliable data instead of those which are complex but unreliable. The main intention of the study is calculating natural ventilation hours, i.e., to ascertain when to open or not to open the windows for maintaining thermal comfort. Whether these will be opened by the occupants is not examined. Therefore, because of the absence of a reliable window-opening model for the IMMBs, the mixed-mode control for switching between air-conditioning and natural ventilation modes is based on the setpoint temperature control available in EnergyPlus; a control that avoids the simultaneous operation of air conditioning and natural ventilation. Let $\mathrm{T}_{\text {zone }}$ be the zone air temperature in the previous time step, $\mathrm{T}_{\text {out }}$ be the outdoor air temperature, and $\mathrm{T}_{\text {set }}$ be the zone setpoint temperature. This control logic first checks whether $\mathrm{T}_{\text {out }}$ is within the specified lower and upper limits, below and beyond which windows remain closed. The upper and lower limits are considered as 15 and $37^{\circ} \mathrm{C}$ based on the field studies of buildings in India $[19,78]$. Thereafter, either natural ventilation is allowed when $\mathrm{T}_{\text {zone }}<\mathrm{T}_{\text {set, }}$ or the air conditioning is turned on when $\mathrm{T}_{\text {zone }}>\mathrm{T}_{\text {set. }}$ 


\subsection{Application of $U A$ and $S A$ in BPS}

In the BPS, for given input values and model assumptions, output values are obtained by using various underlining mathematical or numerical models. When there is an uncertainty in the input values or these take a range of values, an element of uncertainty also exists in the model output. Understanding the uncertainty in the output value, as well as the influence of various input parameters on its value (thereby making statistical inferences possible) leads to a more nuanced and informed decision-making. This helps in analysing whether the state of knowledge, for example, input values and model assumptions, is sufficient or requires improvement to arrive at a meaningful decision $[86,87]$.

The Monte Carlo (MC)-based global sensitivity analysis (GSA) techniques are used to meet the objectives of the study [88-91]. Nguyen and Reiter [92] conducted a comprehensive review and performance comparison of the various GSA methods for their application in the BPS, including six regression-based, two variance-based, and one screening-based methods. They concluded that variance-based methods provide consistent and reliable results, followed by the screening-based and regression-based methods. However, the former is computationally demanding compared with the latter. For the purpose of this study, the elementary screening of input parameters is of interest in lieu of high accuracy quantitative results. Therefore, as per the recommendations of Menberg et al. [93] and Nguyen and Reiter [92], this study uses two fundamentally different and relatively computationally less demanding methods for the purpose of UA and SA: the regression-based method with standardised regression coefficients (SRC) (for both UA and SA) and the Morris elementary effects (EE) method (for SA only).

\subsection{Workflow}

The Monte Carlo-based GSA analysis consists of three steps: generating input samples, 
conducting EnergyPlus model runs to generate output results, and analysing output results for uncertainty and sensitivity. The workflow for the present study is accomplished as follows:

(1) Input sampling: For the SRC, input samples based on the Latin hypercube sampling are generated using the SimLAB software $[89,94,95]$. For the Morris EE method, the input samples based on enhanced sampling for uniformity are generated using the MATLAB code 'Global Sensitivity Analysis: Elementary Effects Method of Morris using Sampling for Uniformity (SU)' [96,97].

(2) Model runs: Parametric simulations are conducted using jEPlus, a parametric batch tool for EnergyPlus [98,99].

(3) Output analysis: For the SRC output results, R code is used for generating the empirical cumulative distribution function (ECDF); histogram and boxplot are used for conducting UA; R package 'sensitivity' is used to conduct SA [100,101]. For the Morris EE output results, SA is performed by using the MATLAB code mentioned above.

For a smooth workflow among the tools, first, a master spreadsheet containing all input parameters is developed. Then, python scripts are used to generate the required input and output intermediary files to exchange information between the master spreadsheet and different tools: SimLAB, EnergyPlus, jEPlus, R, and MATLAB.

\subsection{Input parameters}

The specific inputs for various building design and control parameters are listed in the succeeding sub-sections together with their distribution type and range for the MC analysis. Literature review, the ECBC, and the national building code (NBC) are considered for selecting the input parameters and their range of values. Although few input parameters are 
beyond their scope, they are included in the study in an attempt to understand the influence of diverse input parameters.

\subsubsection{Climate and micro-climate}

The three predominant hot climates of India (as per ECBC classification) — warm and humid, hot and dry, and composite climates — are considered in the study. They are classified according to their mean monthly maximum temperatures $\left({ }^{\circ} \mathrm{C}\right)$ and mean monthly relative humidity (\%). For the warm and humid climate: $>30{ }^{\circ} \mathrm{C}$ (temperature) and $<55 \%$ (humidity); for hot and dry climate: $30{ }^{\circ} \mathrm{C}$ and $>55 \%$; composite climate: $25-30{ }^{\circ} \mathrm{C}$ and $<75 \%[102,103]$. The climate zones (warm and humid, hot and dry, and composite climates) are represented by three cities: Visakhapatnam, Surat, and Bhopal, respectively, which are classified as tier II cities; considerable growth in construction is projected in these cities. They are also selected under the 'smart cities' mission of the Government of India. Weather data in the 'typical meteorological year' format is used for the analysis [104].

In urban areas, the mass and energy balance in micro-climatic environments are affected by the formation of urban canyons and by urban heat island (UHI) effects $[105,106,23,107-109]$. Urban wind speeds are affected by the surroundings. They are calculated using the wind speed profile exponent and wind speed profile boundary layer thickness of an area, which are considered input parameters [110-112] (Table 1). In Indian cities, the UHI effects are of varying intensities (approximately $0.8-10{ }^{\circ} \mathrm{C}$ rise) and periodicities $[113,114]$. However, this study does not directly explain the UHI effects considering the complexity to account for such effects within the TMY weather data. Because this is a large scale BPS study involving various input parameters, the objectives of the study are still achieved [50].

\begin{tabular}{|c|c|c|c|c|c|}
\hline S. No & Parameter & Unit & Distribution & Minimum & Maximum \\
\hline
\end{tabular}




\begin{tabular}{|c|c|c|c|c|c|}
\hline 1. & Wind speed profile exponent & - & Discrete $^{1}$ & 1 & 5 \\
\hline 2. & Wind speed profile boundary layer thickness & - & Discrete $^{1}$ & 1 & 5 \\
\hline
\end{tabular}

${ }^{1}$ Discrete parameters for terrain: $1=$ Country, $2=$ Suburbs, $3=$ City, $4=$ Ocean, $5=$ Urban

Table 1: Climate input parameters

\subsubsection{Building size and orientation}

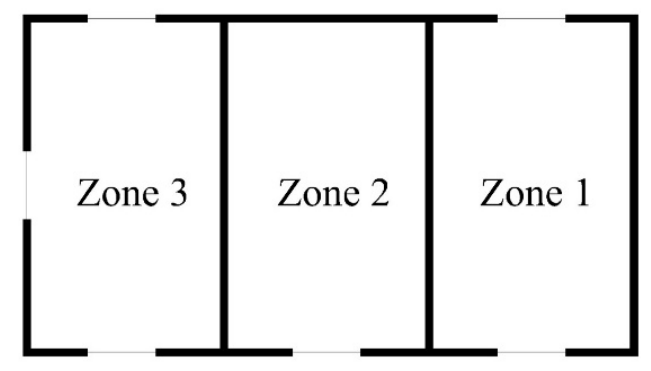

Figure 1: Indicative floor plan

To facilitate the comparison of ventilations from different sides, a three-zone rectangular building consisting of three identical floors is considered for the study (Figure 1). Zones 1, 2, and 3 were considered as double, single, and triple-sided ventilations, respectively. The building size is varied by changing the length and width of the building (Table 2). The maximum length of the building is considered as per the NBC (the NBC recommends limiting the floor depth for naturally ventilated buildings to $15 \mathrm{~m}$ ). The floor to ceiling height is constant at $2.8 \mathrm{~m}$. The wall-to-window ratio (WWR) ranges $10-40 \%$ (the prescriptive requirement of the ECBC limits the WWR to $40 \%$ ). The orientation is considered as an input parameter.

\begin{tabular}{rlclcc}
\hline S. No & Parameter & Unit & Distribution & Minimum & Maximum \\
\hline 1. & Orientation & - & Uniform & 0 & 359 \\
2. & Building length & $\mathrm{m}$ & Uniform & 4.5 & 15 \\
3. & Building width & $\mathrm{m}$ & Uniform & 4.5 & 8 \\
4. & WWR & - & Uniform & 10 & 40
\end{tabular}


Table 2: Building size and geometry input parameters

\subsubsection{Building envelope construction}

The external walls are made of commonly used masonry materials, and the 150 -mm thick roof is reinforced concrete. External insulation is applied to both walls and roof; its material and thickness are varied. The constructions of the ground and internal floors are considered as constants representing a typical construction of a $120-\mathrm{mm}$ thick concrete slab with ceramic tiles. The overall airtightness of the constructions is represented by the crack coefficient value. The window shading effect is assumed within the SHGC value as a multiplier for permanent projections, as per the ECBC. The window inputs also include its discharge coefficient and airtightness. Table 3 summarises all building envelope input parameters.

\begin{tabular}{|c|c|c|c|c|c|c|}
\hline S. No. & Parameter & Unit & Description & Distribution & Minimum & Maximum \\
\hline & External wall & & & & & \\
\hline 1. & Layer-1: Roughness & - & Outer plaster & Discrete $^{1}$ & - & 6 \\
\hline 2. & Layer-1: Thermal absorptance & - & Outer plaster & Uniform & 0.1 & 0.9 \\
\hline 3. & Layer-1: Solar absorptance & - & Outer plaster & Uniform & 0.1 & 0.9 \\
\hline 4. & Layer-1: Visible absorptance & - & Outer plaster & Uniform & 0.1 & 0.9 \\
\hline 5. & Layer-2: Material & - & $\begin{array}{l}\text { External } \\
\text { insulation }\end{array}$ & Discrete $^{2}$ & - & 5 \\
\hline 6. & Layer-2: Thickness & $\mathrm{m}$ & $\begin{array}{l}\text { External } \\
\text { insulation }\end{array}$ & Uniform & 0.025 & 0.1 \\
\hline 7. & Layer-3: Material & - & Masonry & Discrete $^{3}$ & - & 7 \\
\hline 8. & Layer-4: Roughness & & Inner Plaster & Discrete $^{1}$ & - & 6 \\
\hline
\end{tabular}

${ }^{1}$ Discrete parameters for plaster roughness: 1-5: Very Rough - Very Smooth

${ }^{2}$ Discrete parameters for insulation material: 1-Expanded polystyrene, 2-Extruded polystyrene, 3Glasswool, 4-Rockwool, 5-Polyurethane foam

${ }^{3}$ Discrete parameters for masonry material: 1-Red-clay burnt brick, 2-Country kiln-fired brick, 3Compressed mud blocks, 4-Concrete block 25/50, 5-Concrete block 30/60, 6-Resource efficient bricks, 7-Autoclave aerated concrete block 


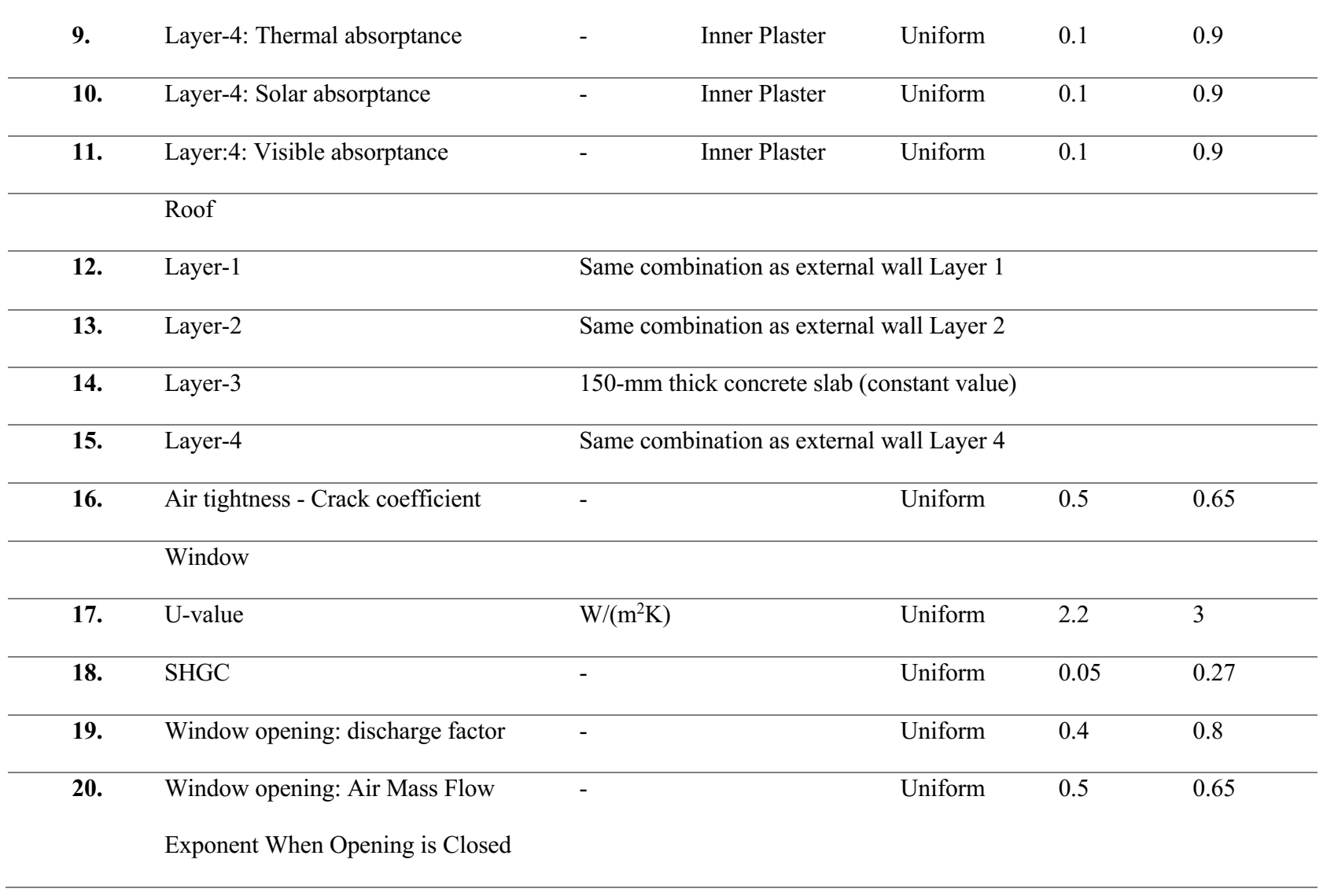

Table 3: Building envelope input parameters

\subsubsection{Internal mass}

The internal mass of the building is composed of elements, such as furniture, interior finishing, and exposed ceilings. It is represented using a special object in EnergyPlus called zone capacitance multiplier. Its range is assumed based on a study by Raftery et al. [59] (Table 4).

\begin{tabular}{|c|c|c|c|c|c|}
\hline S. No & Parameter & Unit & Distribution & Minimum & Maximum \\
\hline 1. & Zone capacitance multiplier & & Uniform & 1 & 2.5 \\
\hline
\end{tabular}

Table 4: Input parameter for internal mass

\subsubsection{Internal heat gains}

The internal heat gains from people, lighting, and equipment are considered as inputs (Table 5). The values for lighting power density (LPD) are based on the ECBC allowances ranging 
from the ECBC to superECBC. People and equipment density values are generally assumed.

The occupancy, lighting, and equipment schedules for the building are based on the ECBC

(Tables 9-10): schedules for daytime-operated business buildings [12].

\begin{tabular}{|c|c|c|c|c|c|}
\hline S. No & Parameter & Unit & Distribution & Minimum & Maximum \\
\hline 1. & People (Zone Floor Area per Person) & $\mathrm{m}^{2} /$ person & Uniform & 1.5 & 5 \\
\hline 2. & Lighting power density ${ }^{1}$ & $\mathrm{~W} / \mathrm{m}^{2}$ & Uniform & 5.4 & 10 \\
\hline 3. & Fraction of lighting power convected as heat & - & Uniform & 0.2 & 0.6 \\
\hline 4. & Equipment power density ${ }^{1}$ & $\mathrm{~W} / \mathrm{m}^{2}$ & Uniform & 3 & 10 \\
\hline 5. & Fraction of equipment power convected as heat & - & Uniform & 0.2 & 0.6 \\
\hline
\end{tabular}

Table 5: Internal load input parameters

\subsubsection{Control strategy}

The cooling setpoint temperature, $\mathrm{T}_{\text {set}}$, is considered as an input parameter for the mixedmode control strategy. Moreover, the minimum venting open factor, and the upper and lower limits of the difference between the indoor and outdoor temperatures that control the venting open factor and modulate the openable window area are considered as inputs (Table 6).

\begin{tabular}{|c|c|c|c|c|c|}
\hline S. No & Parameter & Unit & Distribution & Minimum & Maximum \\
\hline 1. & Cooling Setpoint temperature & ${ }^{\circ} \mathrm{C}$ & Uniform & 22.5 & 28.5 \\
\hline 2. & Minimum Venting Open Factor & - & Uniform & 0.2 & 0.8 \\
\hline 3. & $\begin{array}{l}\text { Indoor and Outdoor Temperature Difference, } \\
\text { Lower Limit for vent opening factor }\end{array}$ & ${ }^{\circ} \mathrm{C}$ & Uniform & 1 & 5 \\
\hline 4. & $\begin{array}{l}\text { Indoor and Outdoor Temperature Difference, } \\
\text { Upper Limit for vent opening factor }\end{array}$ & ${ }^{\circ} \mathrm{C}$ & Uniform & 6 & 10 \\
\hline
\end{tabular}

Table 6: Input parameter for ventilation control strategy

\subsection{Output parameters}

The potential of mixed-mode buildings in India is analysed in terms of three important output parameters: annual cooling energy consumption (ACEI), thermal comfort conditions, and 
natural ventilation (Table 7).

\begin{tabular}{cll}
\hline S. No & Output parameter & Units \\
\hline $\mathbf{1 .}$ & Annual cooling energy consumption (ACEI) & $\mathrm{kW} / \mathrm{m}^{2}$ per year \\
\hline $\mathbf{2 .}$ & Thermal comfort conditions (based on Indian Model for Adaptive & Total number of occupied hours within the \\
& Comfort (IMAC)) & 80 and $90 \%$ comfort bands \\
\hline 3. & Natural ventilation & Total number of hours that a window can be \\
& & kept open for natural ventilation
\end{tabular}

Table 7: Outputs

\section{Results}

In the following sections, first, the convergence criteria and robustness of the results are explained. Thereafter, the three outputs are analysed. This is followed by the discussion on the potential and design implications for IMMBs.

\subsection{Convergence and robustness}

The results of the UA and SA are sensitive to the sample size considered. For the UA and SA to converge to a solution within an acceptable margin of error, the sample size has to be sufficient. For the robustness of results in the study, the convergence of the UA and SA solution is ensured by making it independent from the sample size. For the SRC analysis, 11 model runs with incremental sample sizes of 250, 500, 1000, 2000, 4000, 6000, 8000, 12 000, 16000 , and 20000 are conducted. For the Morris EE method, eight model runs are conducted with the following number of trajectories (sample size $=$ (number of input parameters +1$) \times$ trajectory): $30(1500), 40$ (2000), $50(2500), 60(3000), 70(3500), 100$ (5000), 150 (7500), and 200 (10 000). These sample sizes are initially checked for convergence in multiple zones in the warm and humid climate. The convergence is achieved at a sample size of 16000 for the SRC, and a trajectory of 8 for the Morris EE method. Therefore, these samples sizes are subsequently used for the hot and dry and composite 
climate zones. In the following, the convergence criteria for the uncertainty and sensitivity analyses for representative zones are discussed.

\subsubsection{Convergence criteria for UA}

The convergence criterion for the UA is based on a nonparametric hypothesis test called Kolmonogorov-Smirnov (KS) test. It measures the probability that a chosen univariate dataset is drawn from the same parent population as the second dataset (the two-sample KS test) by computing the maximum distance and KS-test statistic (D) between the ECDFs of the two outputs. The acceptance of the null hypothesis of the KS test shows that the samples come from the same distribution and implies that the result is independent of the sample size. The hypothesis is accepted if the KS-test $\mathrm{p}$-value $>$ significance level (0.05) and KS-test statistic (D) < critical value of the KS-test statistic, $\mathrm{D}_{\text {crit, }}$ which is calculated at the same significance level (0.05). Because the output data contain ties especially for higher sample sizes, a bootstrap p-value is calculated with 1000 bootstrap samples for each KS-test analysis using R package matching [115].

Two sets of KS test are conducted. The first test is between the ECDFs of the output of the lowest (250) and highest (20 000) sample sizes of the same zone. As summarised in Table 8 , the null hypothesis is accepted for a small sample size of 250 , which is sufficient to determine the uncertainty in a single zone. However, the plausibly of the KS-test hypothesis should be rejected for different zones implying that the differences among results are because of factors, such as its floor and ventilation type. This is the purpose of the second test; it is observed that the hypothesis is rejected for sample sizes of 1000 and above.

Set 1 (KS test between ECDFs with sample sizes of 250 and 20000 )

\begin{tabular}{llllll}
\hline Output & KS-test & $\mathrm{D}_{\text {crit }}$ & $\mathrm{p}$-value & Bootstrap p-value & Hypothesis accepted \\
& statistic (D) & & & $(\mathrm{n}=1000)$ & \\
\hline ACEI & 0.05855 & 0.08654987 & 0.3656882 & 0.344 & Yes \\
\hline
\end{tabular}




\begin{tabular}{lccccc}
\hline Hybrid ventilation & 0.04795 & 0.08654987 & 0.6213426 & 0.594 & Yes \\
\hline Thermal comfort & 0.03895 & 0.08654987 & 0.8479499 & 0.806 & Yes \\
\hline Zone load & 0.0359 & 0.08654987 & 0.9079465 & 0.893 & Yes
\end{tabular}

Set 2 Hybrid ventilation (KS test between ECDF zones 1-1 and 1-2 for different sample sizes)

\begin{tabular}{lccccc}
\hline $\mathbf{2 5 0}$ & 0.08 & 0.1216 & 0.4005 & 0.372 & Yes \\
\hline $\mathbf{5 0 0}$ & 0.072 & 0.086 & 0.1497 & 0.131 & Yes \\
\hline $\mathbf{1 0 0 0}$ & 0.0655 & 0.06 & 0.003 & 0.006 & No \\
\hline$\cdots$ & & & & No \\
\hline $\mathbf{2 0 ~ 0 0 0}$ & 0.0653 & 0.0136 & $<2.20 \mathrm{E}-16$ & 0 & No
\end{tabular}

Table 8: Convergence of results for uncertainty analysis based on KS test

\subsubsection{Convergence criteria for $S A$}

The comprehensive convergence criteria for SA based on the GSA techniques require the convergence of three SA parameters: sensitivity indices, ranking (rank correlation coefficient), and screening threshold [116]. The critical sensitivity index for the SRC is the SRC value. For the Morris EE method, critical sensitivity indices are EE absolute mean $\left(\mu^{*}\right)$, EE mean $(\mu)$, and EE standard deviation $(\sigma)$.

\section{(1) Convergence of screening threshold}

The threshold value of the sensitivity index sets the distinction between the influential and non-influential input parameters. It is considered either as an absolute value of a sensitivity index or as a percentage of the index of the most important parameter. In the present study, as per the Morris EE method, parameter screening based on the absolute value (i.e., $\mu * / \sigma>1$ ) or based on percentage (i.e., parameters below the threshold of $5 \%$ of normalised $\mu^{*}$ values) identifies several input parameters as significant, similar to what Menberg et al. [93] has reported. Therefore, the Morris EE method is not used for setting the screening threshold. The accepted practice of selecting an SRC index of $0.05(5 \%)$ of the normalised values of the 
absolute SRC indices shows a clear distinction between the influential and non-influential parameters. Practically, all input parameters above the threshold converged (Figs. 3b, 4b, and 5b) [93]. Therefore, the screening threshold for the present study is set at 0.05 of the normalised absolute SRC values. A further KS-test statistic between the ECDFs of the conditional (influential) and unconditional (non-influential) model outputs for the screening threshold validation does not yield significant results compared with its computational expense; hence, it is not performed further.

(2) Convergence of sensitivity indices

The SRC value and $\mu *$ indicate the sensitivity values for the SRC and Morris EE method, respectively. As per both indices, the most influential input parameters that are above the threshold value converged to $\pm 5 \%$ of the value of the preceding sample size. Few exceptions exist where they converged to a value of $\pm 10 \%$ (results for the SRC only are shown in Figs. 3a, 4a, and 5a). Furthermore, the Morris EE method is used to determine the correlation between the input and output parameters, as the SRC cannot be reliably used for that purpose. For an input parameter, the value of $\sigma / \mu^{*}>1$ indicates that the parameter is nonmonotonic/non-linear or interacts with other parameters. The parameters that vary linearly or monotonically showed a higher degree of convergence in the SRC values; non-monotonic parameters did not appear to converge even after 20000 simulations.

(3) Convergence of sensitivity ranking

For ranking, Sarrazin et al. [116] recommended the use of rank correlation coefficients as convergence criteria. However, Nguyen \& Reiter [92] found that their application in the building simulation context does not yield satisfactory results. They compared the sensitivity analysis based on the SRC and variance-based techniques, such as Sobol or FAST, which are 
capable of dealing with non-monotonicity. They found that although the SRC values overestimated the absolute value of the sensitivity index, the qualitative ranking has been consistent with the Sobol or FAST techniques. Menberg et al. [93] also indicated that the ranking results from the SRC analysis are in good agreement with those of the Morris EE sampling method. Therefore, ranking is based on the absolute lognormal value of the SRC (Figs. 3b, $4 b$, and 5b) and is qualitative. Furthermore, the SRC ranks (Figs. 3c, 4c, and 5c) are compared with the Morris EE ranks (Figs. 3d, 4d, and 5d $\mathrm{d}^{4}$. Both methods exhibit good agreement with respect to the ranking of all input parameters in general and especially for influential input parameters (Figure 2). Moreover, the three output parameters identify the same group of input parameters as the most sensitive, especially for the first 15 influential parameters.

\footnotetext{
${ }^{4}$ Few discrete parameters are considered as dependant parameters to each other for the purpose of simulation. Morris EE assigns the same rank to all dependant parameters. Therefore, there are only 40 ranks for 49 input parameters.
} 


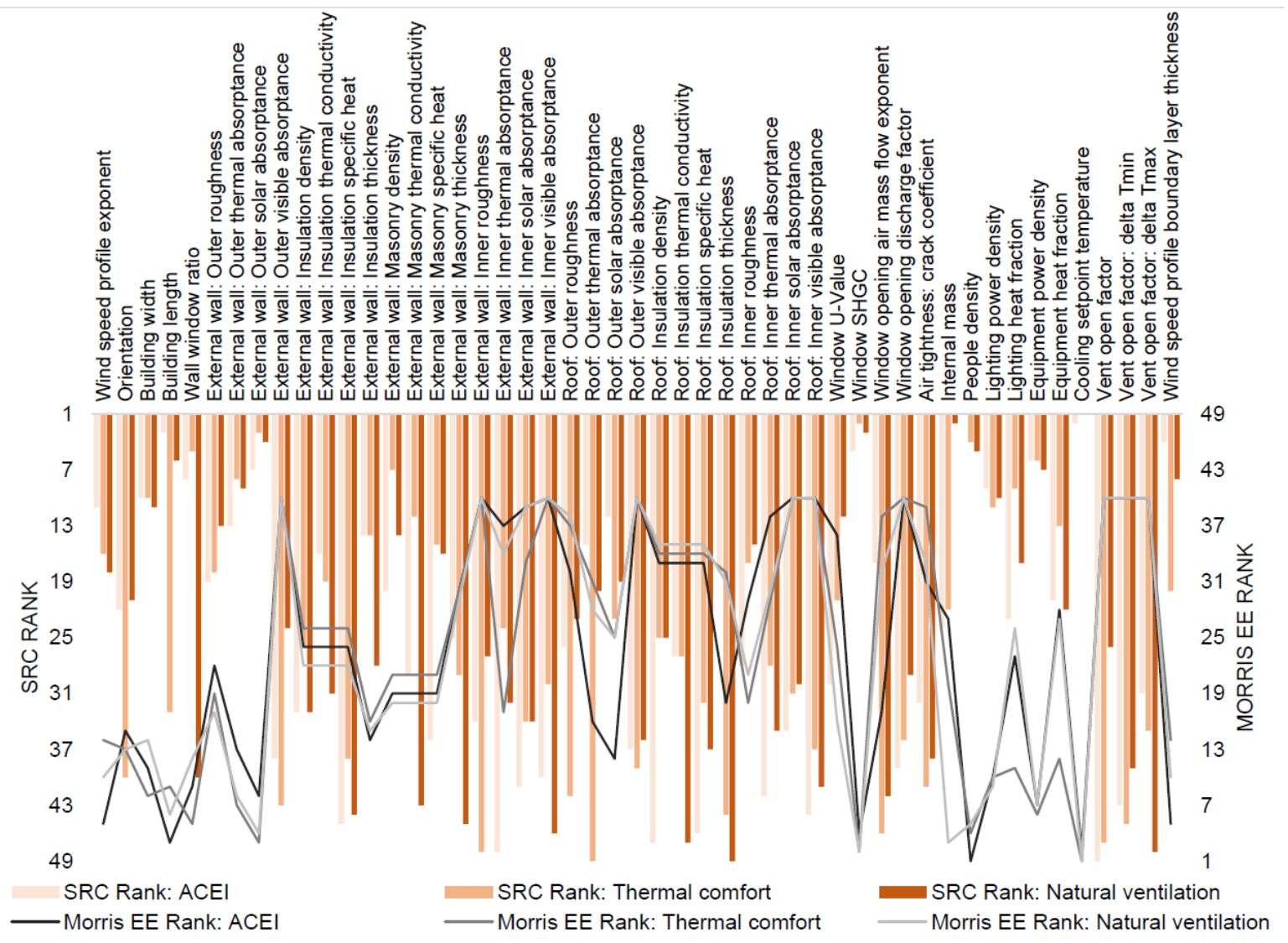

Figure 2: Influence of input parameters as per SRC and Morris EE method

Furthermore, it should be noted that for a high number of input parameters, the convergence of all the three convergence statistics is not guaranteed. Therefore, the reading of results and extractable information is nuanced and based on the comparison of results from both the SRC and Morris EE method [93,116]. In the following section, the convergence of SA indices for ACEI, IMAC, and natural ventilation hours is discussed. The influential input parameters above the sensitivity threshold value are indicated with a horizontal red dotted line (Figs. 3, 4, 5b, 5c, and 5d).

Convergence of sensitivity analysis indices for ACEI

For influential input parameters, the convergence is achieved for both SRC values (Fig. 3a), the SRC rank (Fig. 3c), and Morris EE rank (Fig. 3d). Furthermore, the SRC and Morris 
ranks exhibited good agreement. The Morris EE rank showed better convergence even for parameters below the threshold value.
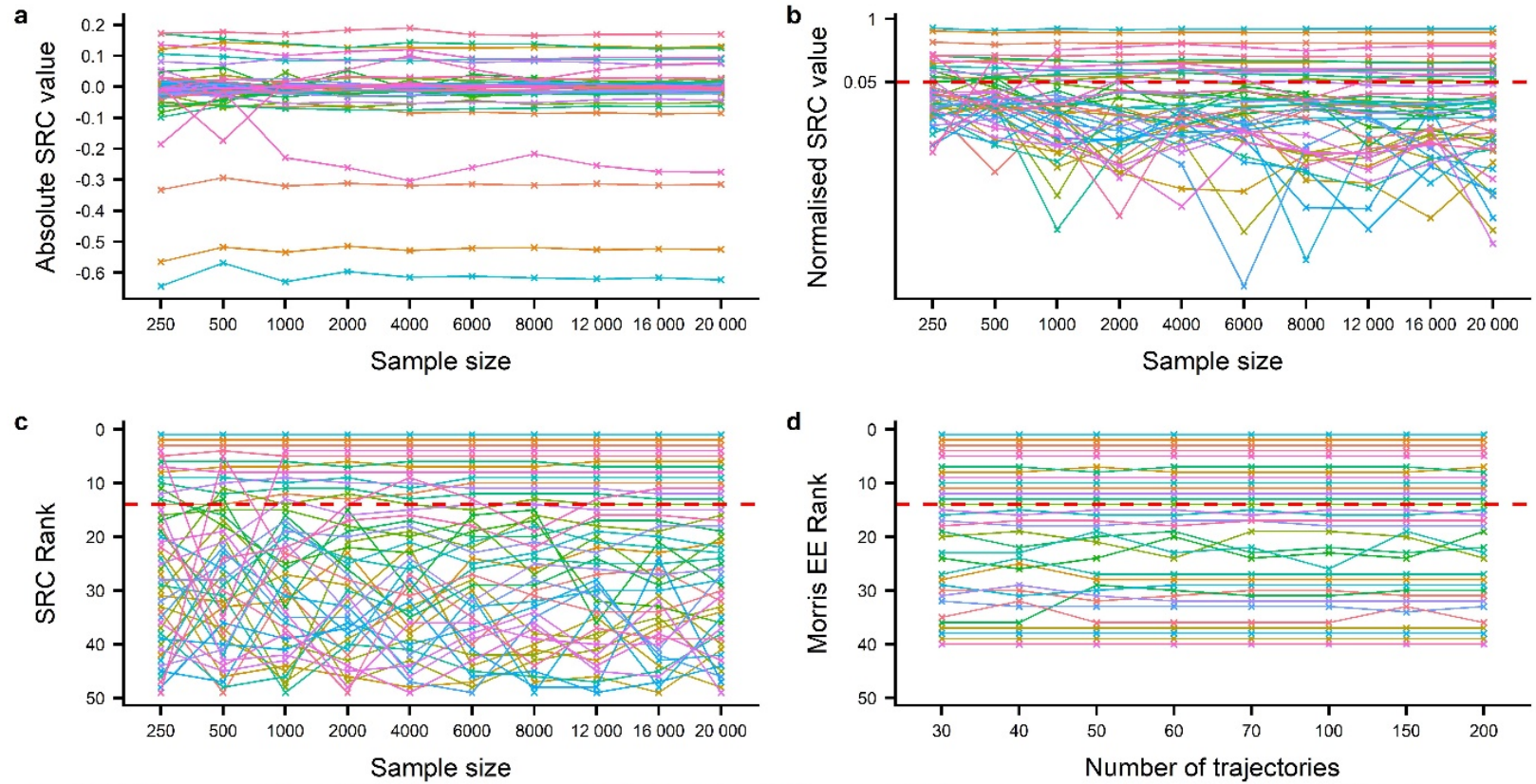

Sample size

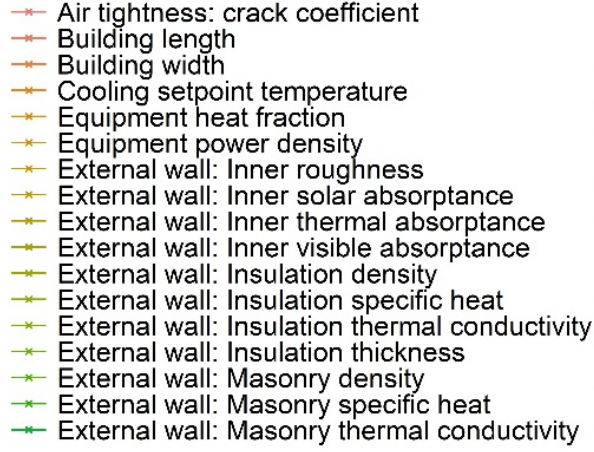

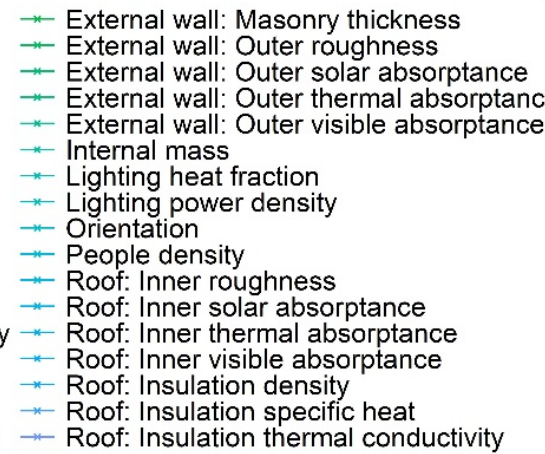

* Roof: Insulation thickness

* Roof: Outer roughness

* Roof: Outer solar absorptance

- Roof: Outer solar absorptance
- Roof: Outer thermal absorptance

* Roof: Outer visible absorptance

* Vent open factor

* Vent open factor: delta Tmax

* Vent open factor: delta Tmin

* Wall window ratio

*-Wind speed profile boundary layer

$\rightarrow$ Wind speed profile exponent

* Window opening air mass flow exp

* Window opening discharge factor

* Window SHGC

* Window U-Value

Figure 3: Convergence of sensitivity analysis indices for ACEI

Convergence of sensitivity analysis indices for thermal comfort

For influential input parameters, the convergence is achieved for both SRC values (Fig. 4a,

4b), the SRC rank (Fig. 4c), and the Morris EE rank (Fig. 4d). Furthermore, the SRC and

Morris ranks exhibited good agreement. However, unlike the convergence pattern observed

in ACEI, the non-influential input parameters below the threshold value do not converge. 

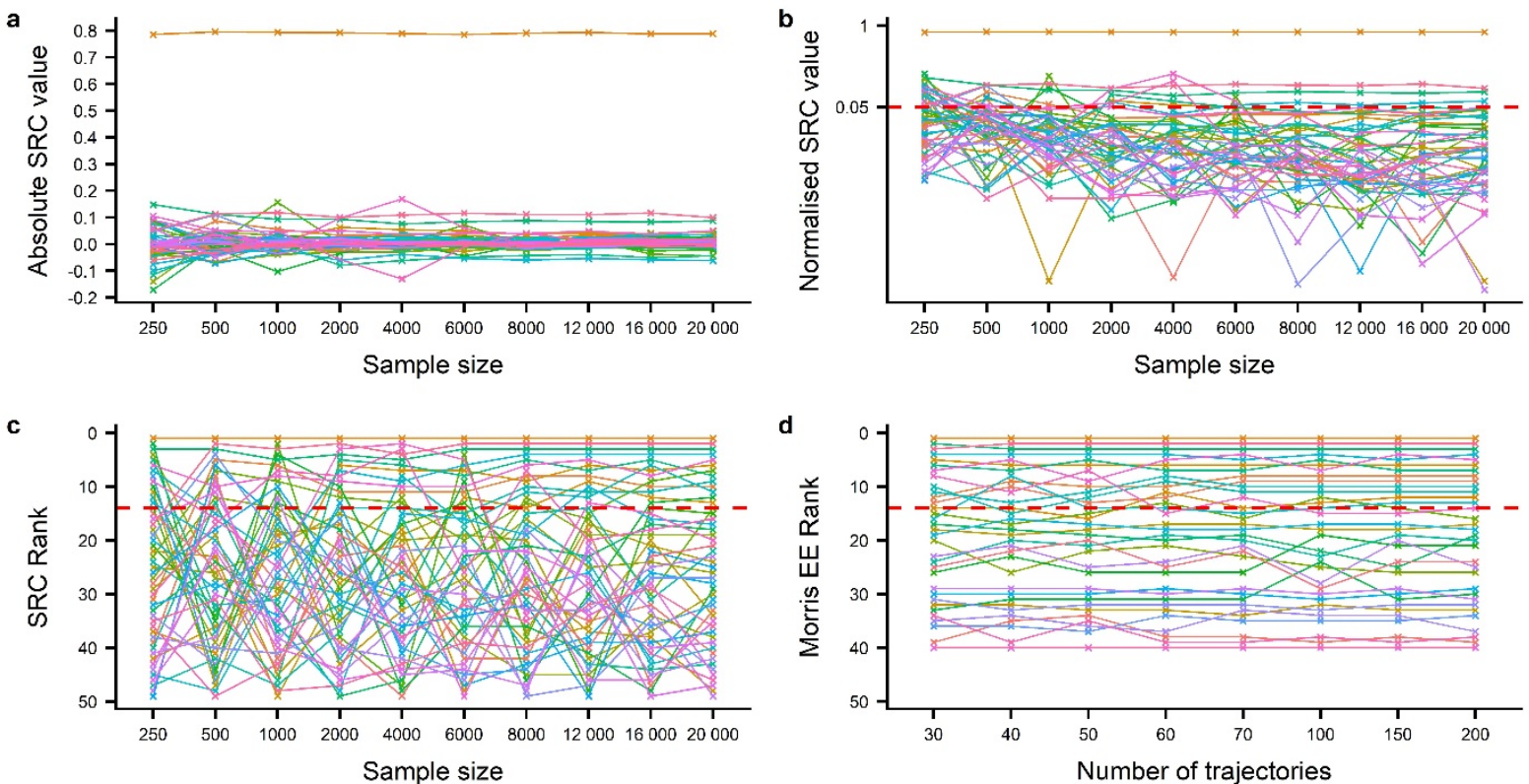

\begin{tabular}{|c|c|}
\hline at te & 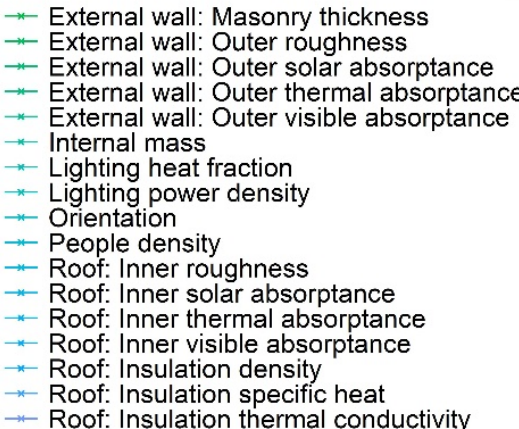 \\
\hline
\end{tabular}

* Roof: Insulation thickness

* Roof: Outer roughness

- Roof: Outer roughness

- Roof: Outer solar absorptance

* Roof: Outer thermal absorptance

* Vent open factor

* Vent open factor: delta Tmax

* Vent open factor: delta Tmin

* Wall window ratio

* Wind speed profile boundary layer

* Wind speed profile exponent

* Window opening air mass flow exp

* Window opening discharge factor

* Window SHGC

* Window U-Value

* External wall: Masonry thermal conductivity $\rightarrow$ Roof: Insulation thermal conductivity

Figure 4: Convergence of sensitivity analysis indices for thermal comfort

Convergence of sensitivity analysis indices for natural ventilation hours

The convergence pattern is similar to the thermal comfort. All influential parameters above

the threshold value have converged (Fig. 5). 

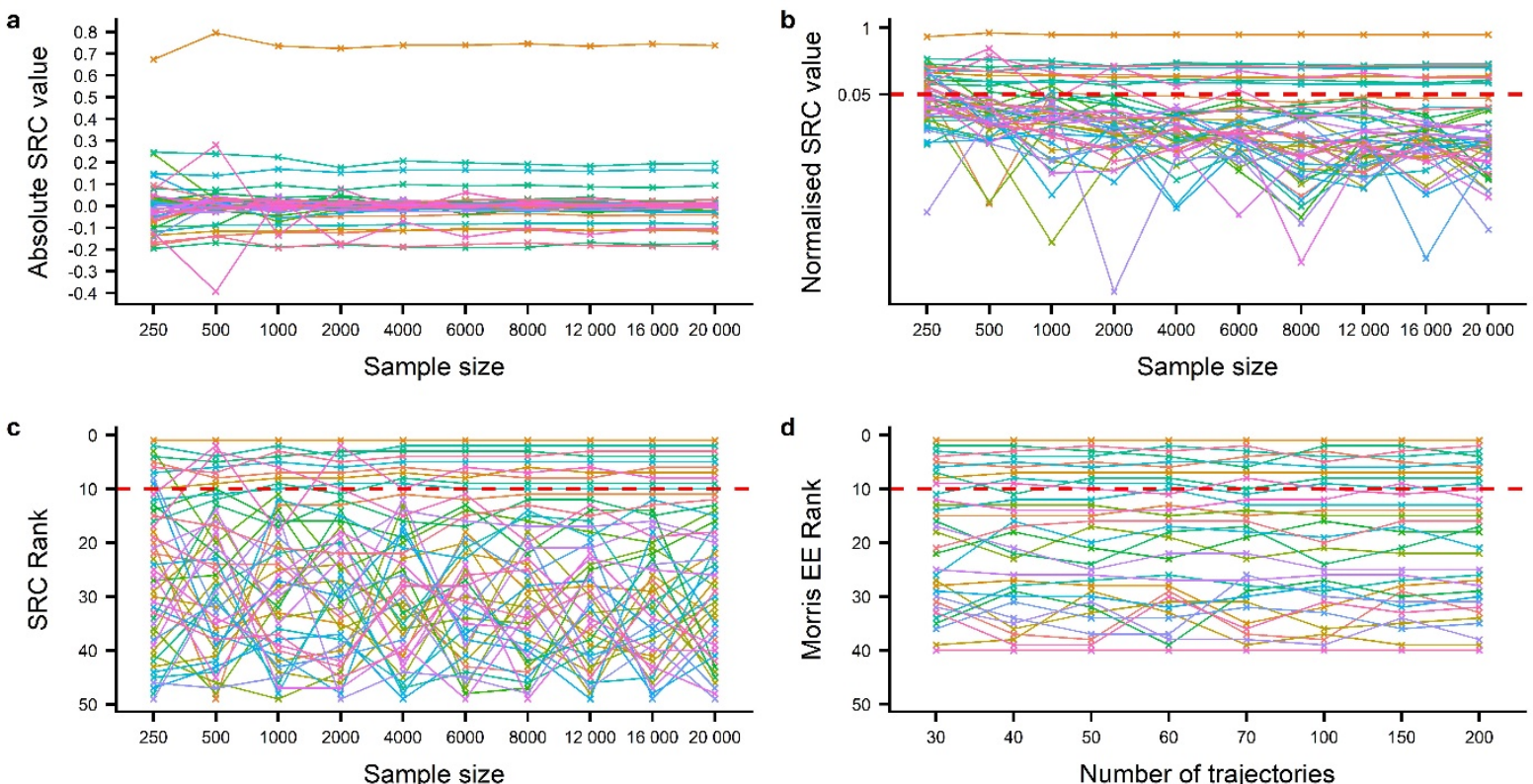

* Air tightness: crack coefficient Sample size

*- Building length

* Building width

- Cooling setpoint temperature

Equipment heat fraction

Equipment power density

External wall: Inner roughness

External wall: Inner solar absorptance

External wall: Inner thermal absorptance

External wall: Inner visible absorptance

External wall: Insulation density

External wall: Insulation specific heat

* External wall: Masonry thickness

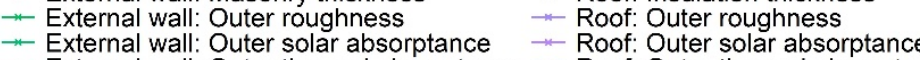

Number of trajectories

* Roof: Insulation thickness

* External wall: Outer thermal absorptance $*$ Roof: Outer thermal absorptance

* External wall: Outer visible absorptance * Roof: Outer visible absorptance

* Internal mass

* Lighting heat fraction

* Lighting power density

* Orientation

* People density

* Roof: Inner roughness

\#- Roof: Inner roughness

External wall: Insulation thermal conductivity - - Roof: Inner thermal absorptance

External wall: Insulation thickness

* External wall: Masonry density $\quad *$ Roof: Insulation density

$\begin{array}{ll}*-\text { External wall: Masonry specific heat } & * \text { Roof: Insulation specific heat } \\ * \text { External wall: Masonry thermal conductivity } & \rightarrow \text { Roof: Insulation thermal conductivity }\end{array}$

Vent open factor

* Vent open factor: delta Tmax

* Vent open factor: delta Tmin

* Wall window ratio

* Wind speed profile boundary layer

* Wind speed profile exponent

* Window opening air mass flow exp

* Window opening discharge factor

* Window SHGC

Figure 5: Convergence of sensitivity analysis indices for natural ventilation hours

\subsection{Analysis}

In the following, the potential of the three output parameters using the UA is first analysed;

thereafter, influential input parameters are analysed using SA.

The potential is analysed through the ECDFs of output values (Figs. 6a, 8, and10). In

the ECDF graphs, a high probability of occurrence along the y-axis for any given value along the $\mathrm{x}$-axis indicates a higher potential for that specific output compared with the other outputs [90].

The normalised SRC values for influential input parameters are shown on the y-axis.

The corresponding floor, climate zone, and ventilation type for representative zones are 
shown on the X-axis (Figs.7, 9, and 11); for the output ACEI, only climate zones are shown on the X-axis (Fig. 7). In addition to the SRC values, the correlation between the input and output parameters is provided in the adjacent brackets. The correlation is identified as linear, monotonic, almost monotonic, and non-monotonic/non-linear as per the Morris EE method. The corresponding sign convention is obtained from the SRC values. However, for nonmonotonic input parameters, the SRC sign convention may not be reliable although it is found to be consistent among most of the influential parameters; it is only provided for information purposes. Non-monotonic/non-linear correlation indicates that the specific input parameter is either always non-monotonic or exhibits strong interaction with other input parameters. This can only be explained further through variance-based SA analysis, which accounts for higher order effects.

\subsubsection{Annual Cooling Energy Intensity (ACEI)}

\subsubsection{Potential analysis}

Figure 6a shows the ECDFs for ACEI in the three climate zones. The incidence of higher values for ACEI is higher in the warm and humid climate followed by the hot and dry and composite climates, as these two latter climates have cold winter and lean seasons. The frequency of occurrence of the peak ACEI values is lower in the warm and humid climate zone compared with the other two (Fig. 6b). The results indicate extremely low probabilities for both lower and higher values of ACEI. Furthermore, the thermal comfort model and control strategy adopted in the present study has resulted in a broad comfort band, from IMAC 90 to 80 . Therefore, ACEI values are analysed in relation to the thermal comfort and natural ventilation results to ascertain the potential of the IMMBs as presented in the section 4, discussion. 


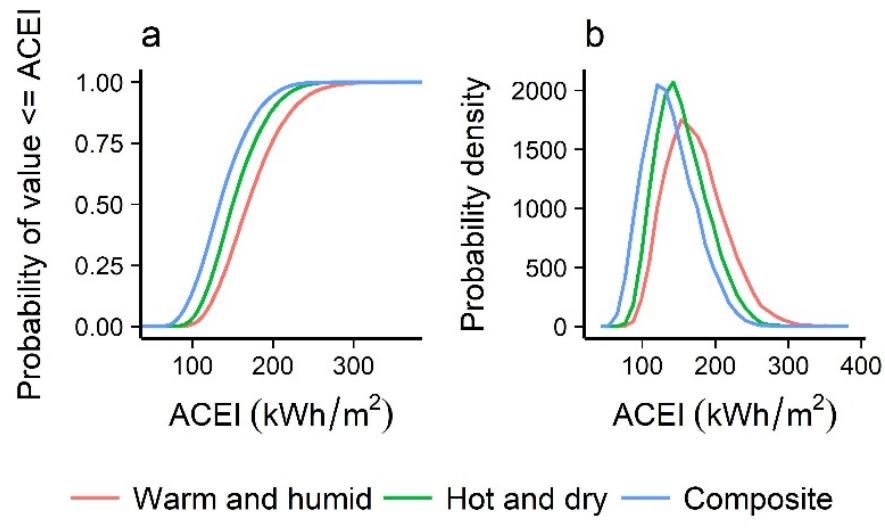

Figure 6: Distribution of ACEI under different climates

\subsubsection{Influential parameters}

Figure 7 shows the most influential input parameters for ACEI. Across the climate zones, the cooling setpoint temperature and people density ${ }^{5}$ were identified as the most influential parameters with negative and positive correlations, respectively. As lighting becomes more efficient, internal heat gains from equipment and occupants become critical to reduce ACEI. The building length exhibited a negative correlation, indicating that the resultant savings from the mixed-mode operation decrease with the increase in building size. Surface properties of the external wall and roof, and solar and thermal absorptances are more influential than their construction properties. All surface properties, except the thermal absorption of the external wall, has a negative correlation. This indicates that the night time heat loss to the surroundings through longwave emissivity is equally important or more important than minimising the daytime short-wave solar heat gain. This shows the importance of the day and night direction of heat transfer through the wall of mixed-mode buildings in India, as they are not ventilated at night. Although lower in the order of influence, the external wall thermal insulation thickness is found to be influential only in the

\footnotetext{
${ }^{5}$ Sign convention for people density (persons per floor area) is used
} 
hot and dry climate. The window area and SHGC display a positive correlation. The local wind speed exhibits a positive correlation with ACEI, and shows a higher influence under the warm and humid climate compared with the other two climates. This is counterintuitive because buildings in the warm and humid climate are designed to maximise natural ventilation by taking advantage of higher wind speeds. However, during the air-conditioning period in mixed-mode buildings, this may act counterproductive.

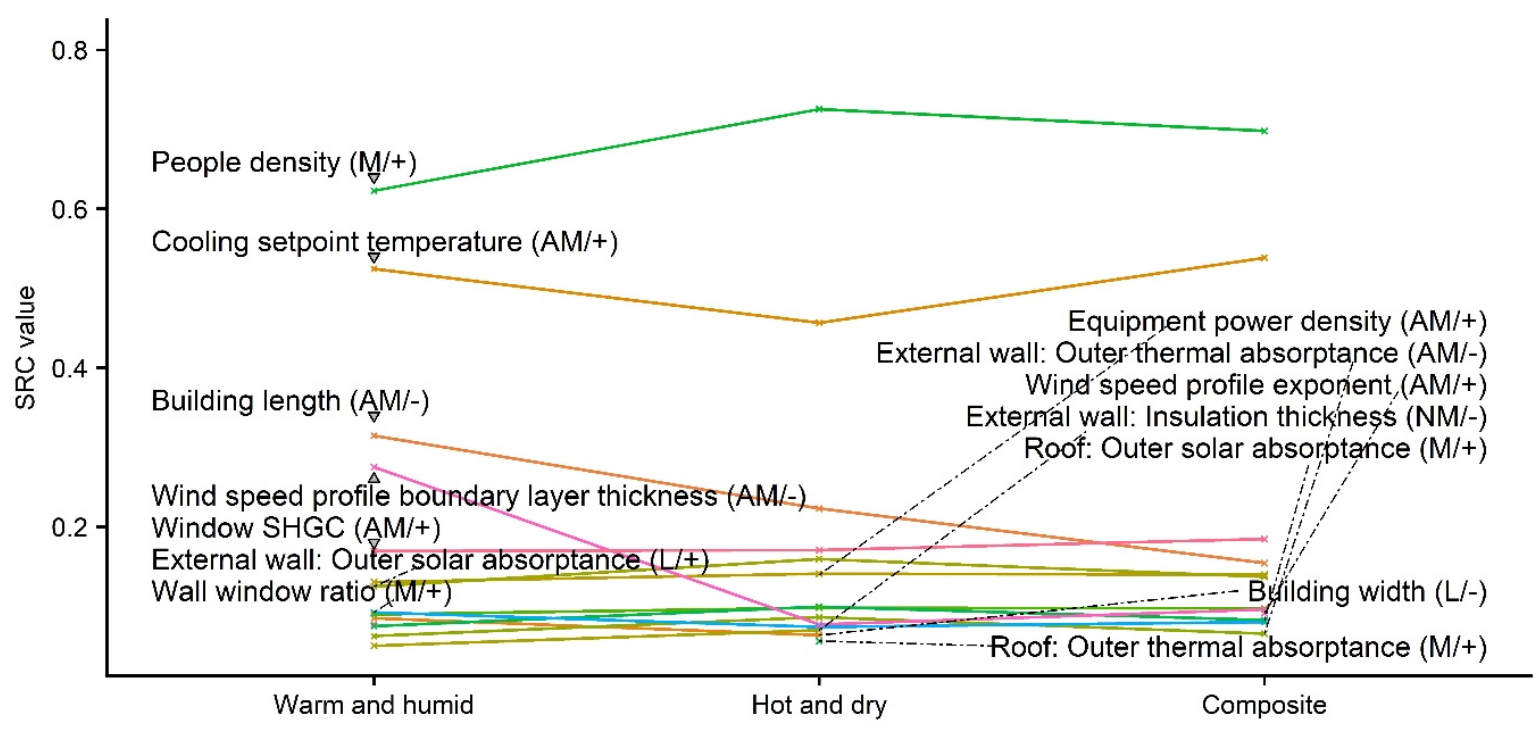

M: Monotonic; L: Linear; AM: Almost monotonic; NM: Non-monotonic/non-linear; +/-: Correlation.

Figure 7: Sensitivity indices of influential input parameters for ACEI

\subsubsection{Adaptive thermal comfort}

\subsubsection{Potential analysis}

The ECDFs for thermal comfort as per IMAC 90 and 80 are presented for a representative zone in Fig. 8. The results are summarised in the way shown in the figure because the distributions for different zones (in terms of floors), ventilation type, and across climate zones are remarkably similar. For objectivity, two vertical dotted lines represent 5\% (162) and $10 \%$ (324) of the total occupancy hours of $3240 \mathrm{~h}$. Even below a threshold level of 5\%, 
there are virtually no occupancy hours outside of IMAC 80 band. This is perhaps because of its high bandwidth $(\varepsilon=5.9)$. It indicates that irrespective of the design and control inputs, IMAC 80 band is easily achievable. There is a $50-60 \%$ probability that the number of building occupancy hours outside of IMAC 90 lies within the threshold level of 5-10\% in all building zones and across climates. Furthermore, the ground floor shows a slightly higher probability of achieving thermal comfort compared with those of the other floors; there is only a marginal difference between zones with single, double, and triple-sided ventilations.
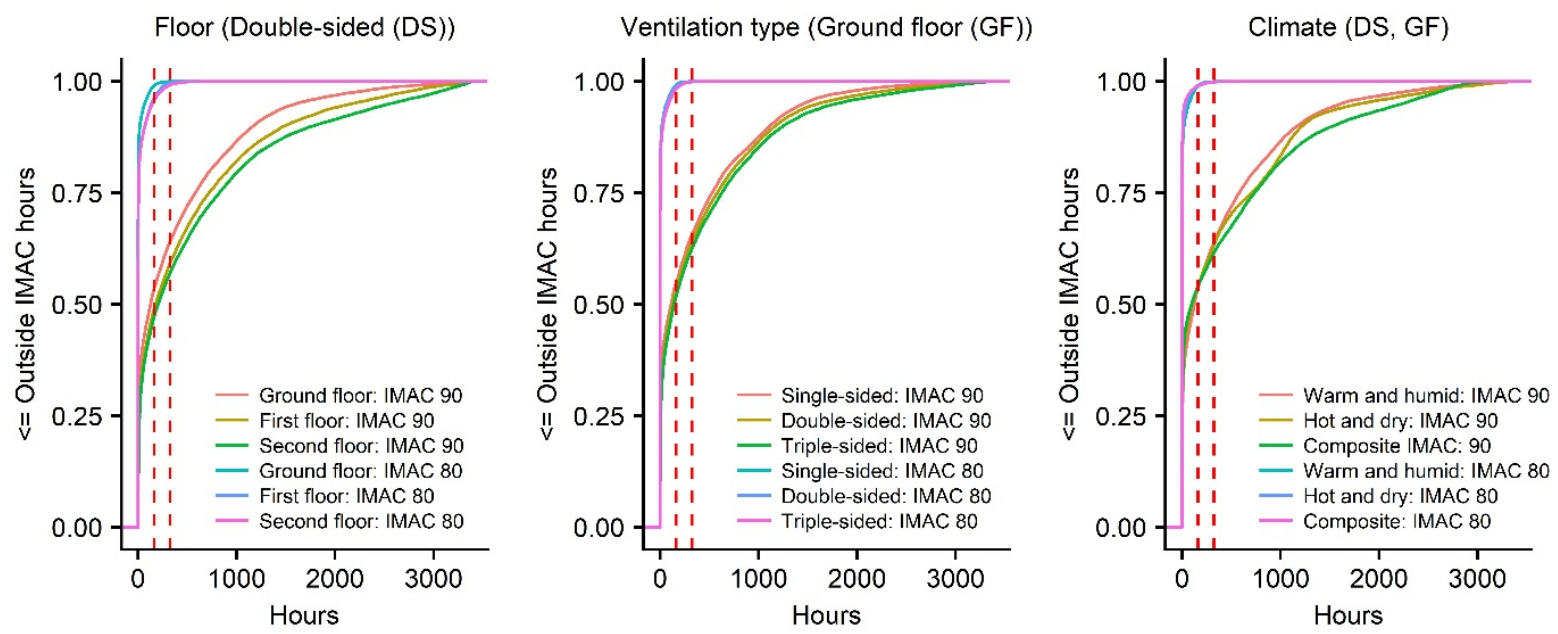

Figure 8: Floor, ventilation type, and climate comparison in terms of thermal comfort potential

\subsubsection{Influential parameters}

Figure 9 shows the most influential input parameters for the thermal comfort as per IMAC 90. The cooling setpoint temperature is the most influential parameter and exhibits a positive correlation with the occupancy hours outside of IMAC 90 band. Except for the cooling setpoint temperature, most parameters are non-monotonic or exhibit parameter interactions. The internal heat gains from people and equipment are found to be influential. The window SHGC influence increases with the ventilation sides; this appears to indicate that the window 
area and SHGC have to be minimised. The surface properties of the building envelope, and solar and thermal absorptances are identified as influential parameters. In the composite climate zone, the local wind speed and building size are identified as influential parameters.

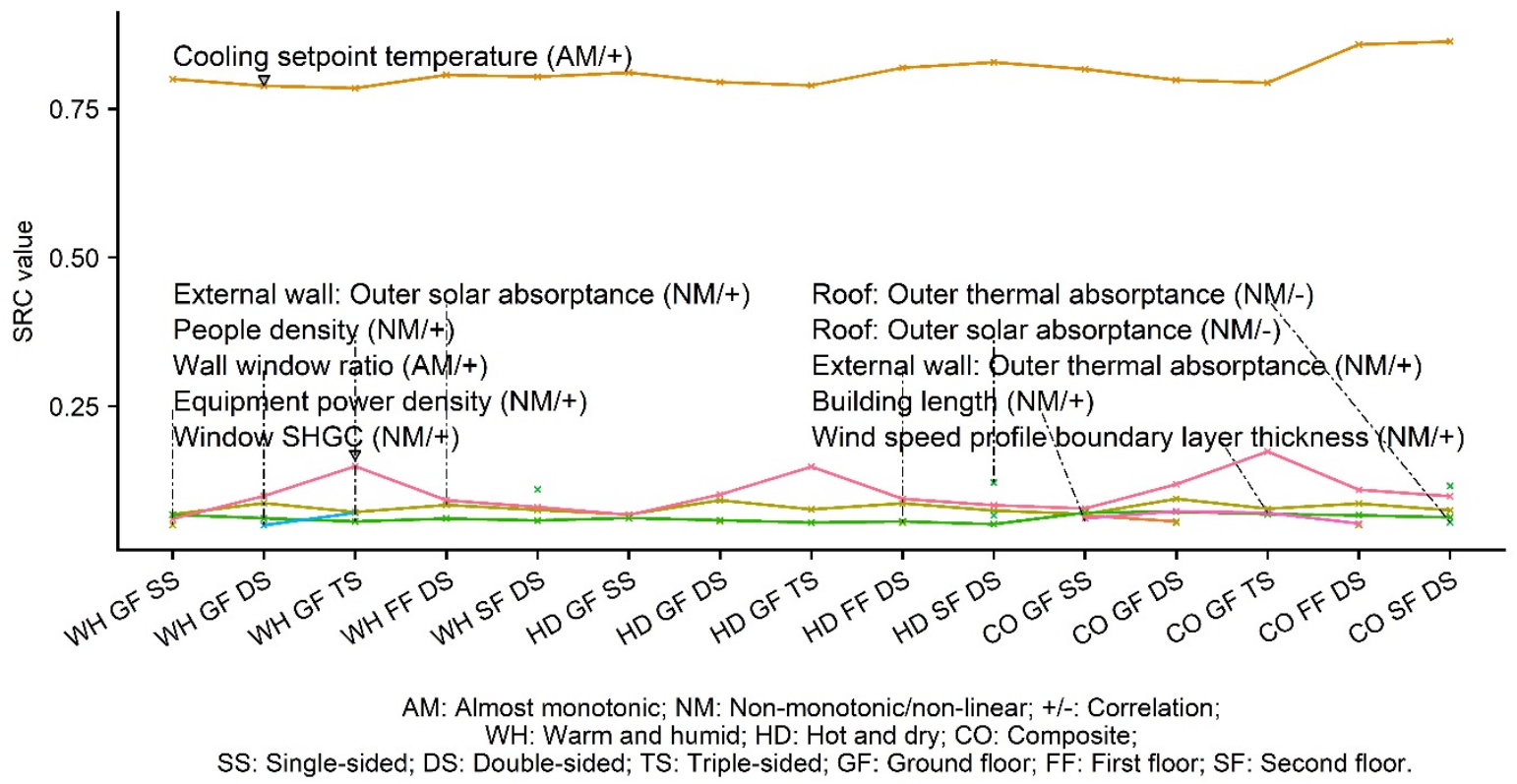

Figure 9: Sensitivity indices of influential parameters for thermal comfort

\subsubsection{Natural ventilation hours}

\subsubsection{Potential analysis}

Figure 10 shows the comparison of ECDF hours of natural ventilation in terms of the floor (first row), ventilation type (second row), and climate zone (third row). A time step of 20 min has been used in the present BPS study. However, the comparison results of natural ventilation hours indicate that it is extremely improbable that their variations will be significant at a lower or higher timestep for the purpose of the present study. For objectivity, the vertical dotted lines indicate 5 and $10 \%$ of the total occupancy hours. For different floors and ventilation types, the difference among their probabilities of occurrence of natural ventilation hours is only marginal. Nevertheless, the second floor has a slightly higher 
potential compared with those of the ground and first floors. This indicates that for low-rise buildings, floor height from the ground and ventilation type do not have a significant effect on the hours of natural ventilation. In general, the maximum potential for hours of natural ventilation remained at approximately $10 \%$ of the occupancy hours in the warm and humid, and hot and dry climates. The composite climate clearly display a higher potential for hours of natural ventilation.
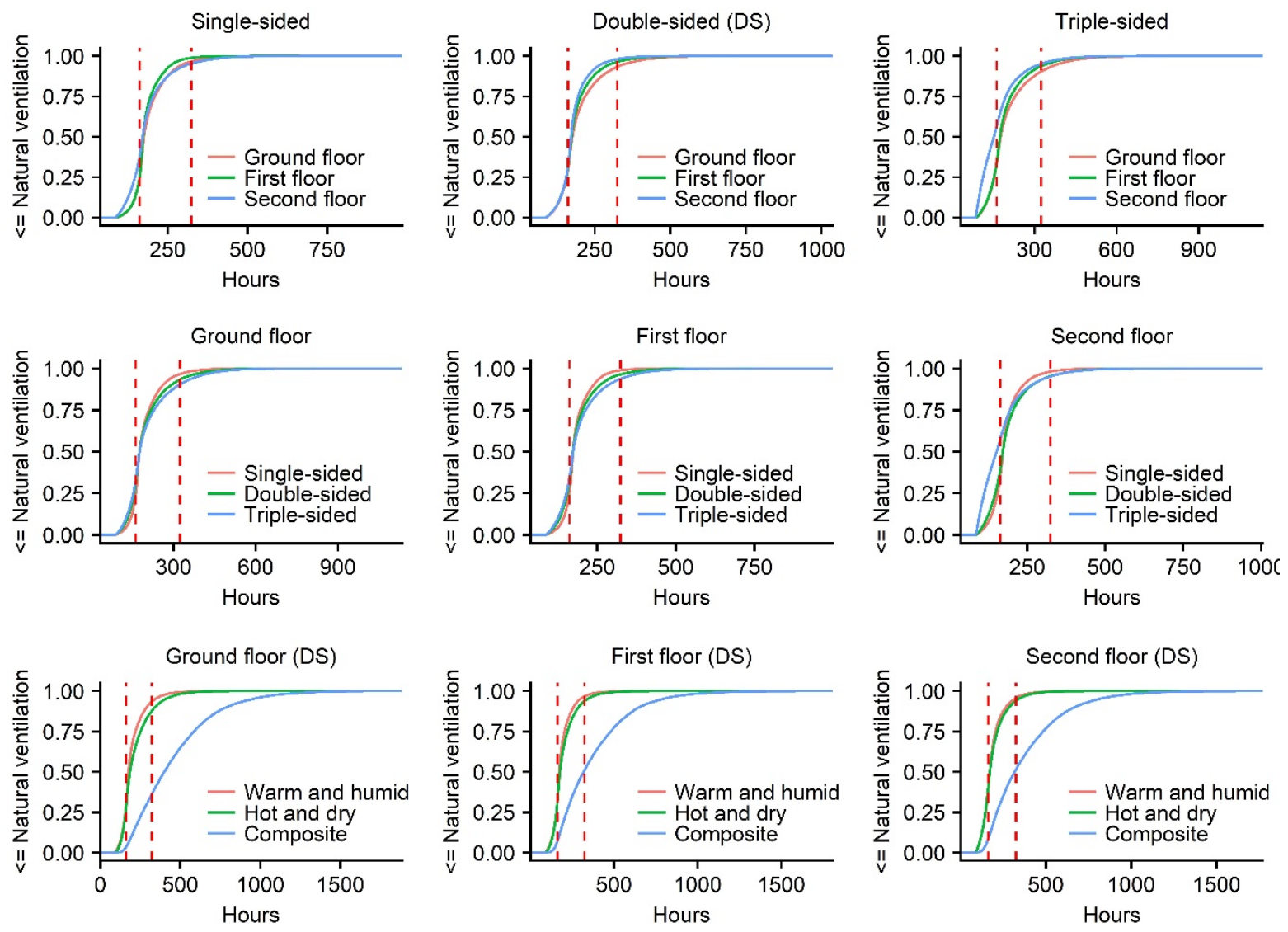

Figure 10: Comparison of natural ventilation in terms of floor, ventilation type, and weather

\subsubsection{Influential parameters}

Figure 11 shows the most influential input parameters for the hours of natural ventilation.

The cooling setpoint temperature is the most influential parameter with a positive correlation with hours of natural ventilation. An increase in the internal mass increased the number of 
hours of natural ventilation. Its influence is more evident in the warm and humid climate than in the other two climate categories. The internal gains and window SHGC are identified as influential parameters. The window area is an influential parameter in double and triple-sided ventilation zones in the hot and dry, and composite climates. The zone lengths have a negative correlation with the number of hours of natural ventilation, implying that the zone depth should be maintained as low as possible for effective natural ventilation. The external wall surface parameters, and solar and thermal absorptances are also influential parameters. The wind speed is influential in zones with double and triple-sided ventilations; however, its magnitude is considerably higher in the former than in the latter.

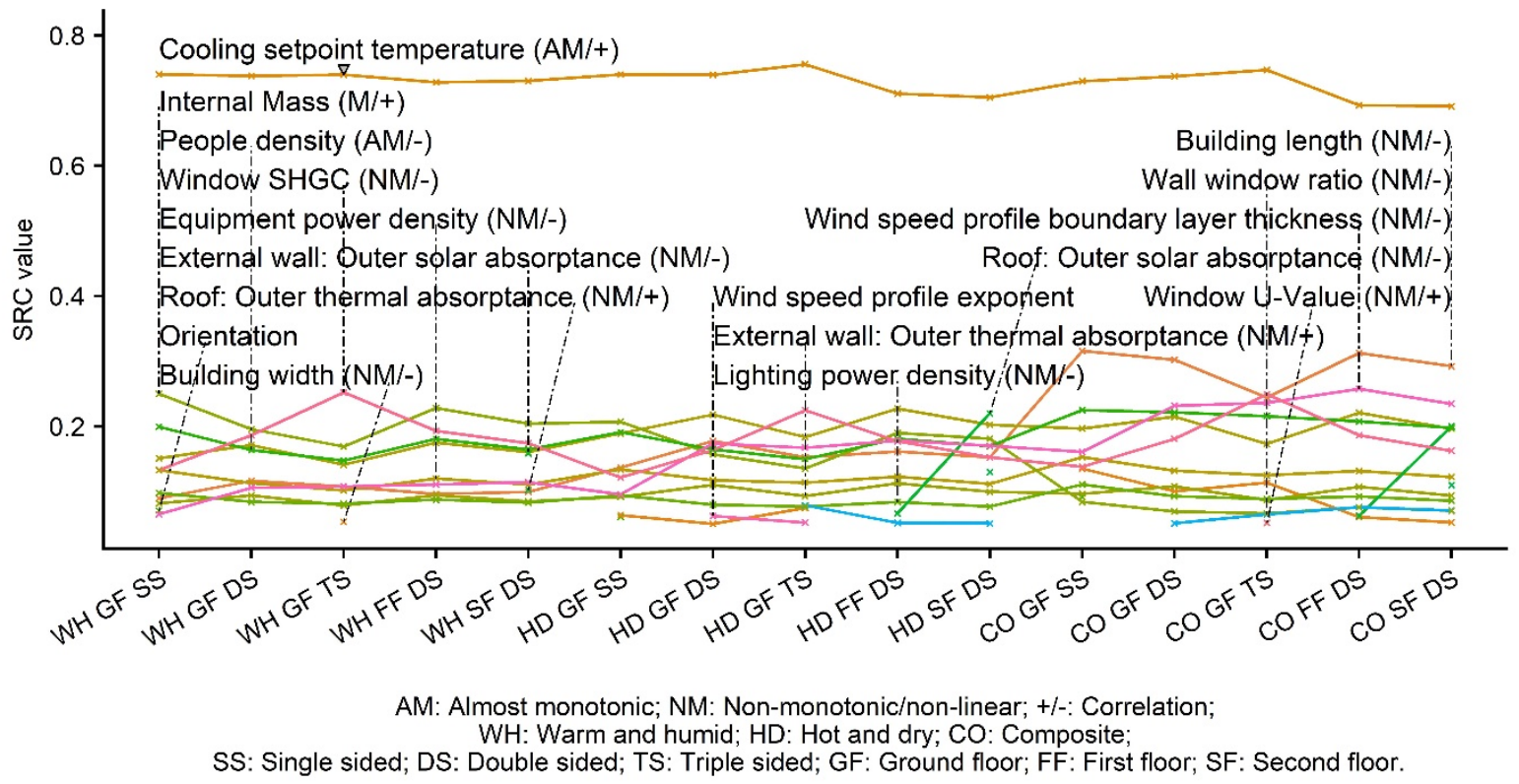

Figure 11: Sensitivity indices of influential parameters for natural ventilation

\section{Discussion}

\subsection{Potential of mixed-mode buildings}

The higher number of thermal comfort and natural ventilation hours at the minimum ACEI values indicates a higher potential for mixed-mode buildings. In the present analysis, the potential is analysed together with the most influential input parameter, cooling setpoint 
temperature and the three outputs, ACEI, thermal comfort conditions, and natural ventilation hours. Figure 12 shows the scatterplot, boxplot (showing the first, median, and third quartile) with whiskers (showing the minimum and maximum values at either ends and outliers as solid dots), and causal correlation curves for ACEI, hours of natural ventilation, and thermal comfort conditions. For objectivity, the horizontal red dotted lines represent 5 and $10 \%$ of the total occupancy hours. The box width is proportional to the square roots of the number of observations in the groups. The y-axis represents the values of all output results, and the $\mathrm{x}-$ axis represents the most influential parameter-the cooling setpoint temperature.
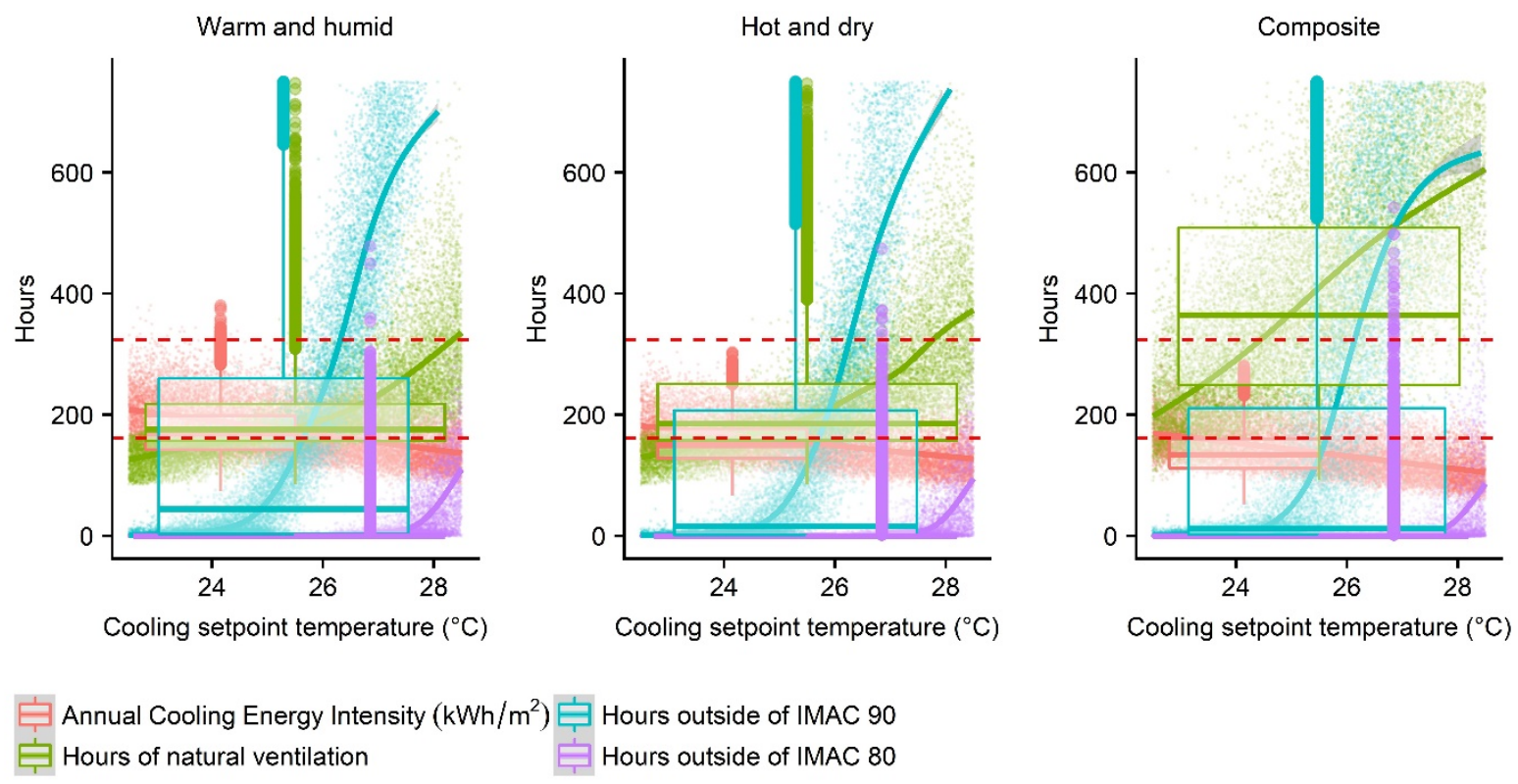

Figure 12: Hours of hybrid ventilation with respect to the thermal comfort, ACEI, and cooling setpoint temperature

With an increase in the number of natural ventilation hours, ACEI decreased. However, this also corresponded with an increase in the cooling setpoint temperature. The median and third quartile values of naturally ventilated hours lie between 5 and $10 \%$ of the occupied hours in the warm and humid, and hot and dry climates and beyond $10 \%$ in the composite climate. This do not appear to indicate a considerably high potential for natural ventilation hours. Therefore, the decrease in ACEI could be attributed to an increase in the 
cooling setpoint temperature rather than a paltry increase in the number of natural ventilation hours.

The occupancy hours outside of IMAC 80 band do not exceed the 5\% threshold, even when the cooling setpoint temperature reaches $28^{\circ} \mathrm{C}$ in all the three climate zones. The median values of IMAC 90 are well below the 5\% threshold, and the third quartiles lie between 5 and $10 \%$. For all the climate zones, the causal correlation curve indicates that the occupancy hours outside of IMAC 90 stay relatively low until the temperature is $25^{\circ} \mathrm{C}$; beyond which they increase exponentially. However, they remain below the $10 \%$ threshold until approximately $26^{\circ} \mathrm{C}$. The Indian Model for Adaptive Comfort is based on indoor operative temperatures. A floating setpoint temperature based on the operative temperature reduces the cooling energy consumption compared with a fixed cooling-air setpoint temperature because it enables the achievement of thermal comfort (specifically, the ATC) at higher air setpoint temperatures [64]. It is plausible that higher cooling setpoint temperatures beyond $26{ }^{\circ} \mathrm{C}$ result in higher instances of operative temperatures above IMAC 90 band. This implies that in a higher comfort band, a reasonable degree of thermal comfort satisfaction, IMAC 90 , can be achieved at cooling setpoint temperatures as high as $26^{\circ} \mathrm{C}$.

In summary, ACEI, thermal comfort, and natural ventilation hours put together indicate that mixed-mode control based on higher cooling setpoint temperatures do not appear to increase the natural ventilation hours substantially because they simultaneously increase the thermal discomfort (bases on IMAC 90). However, it still aids in reducing the ACEI during the air-conditioning period, i.e., in IMMBs, significant energy savings do not result from air-conditioning reduction. Instead, energy savings result from design parameters, and most importantly, the cooling setpoint temperature increases. 


\subsection{Design implications for mixed-mode buildings}

In IMMBs, ACEI is significantly influenced by the cooling setpoint temperature, internal heat gains, building size and geometry including shading/SHGC, and the building envelope external surface properties compared with the thermophysical properties of building constructions. The lower U-values for the building envelope are well suited for fully airconditioned buildings [117]. However, in IMMBs, although the highly insulated envelope makes the buildings efficient during cooling, it could also extend the cooling period as a result. The building becomes increasingly uncomfortable during the natural ventilation period because of thermal insulation; this leads to an increase in the air-conditioned period and reduces the mixed-mode potential. This study further shows that the insulation thickness is one of the least influential input parameters. Consequently, this calls into question the applicability of highly insulated building envelope in IMMBs.

The overall potential for natural ventilation by opening the windows remained insignificant in general, especially in the warm and humid, and hot and dry climate zones. Although, not presented in the results, the internal mass is identified as an influential parameter in zone loads. The importance of internal mass, which has also been identified as an influential parameter for natural ventilation hours, is often overlooked and should be further explored. Moreover, measures to increase natural ventilation in warm and humid climates, such as exposing the building to wind, appear to increase cooling energy consumption. It is uncertain whether the control strategy based on the operative temperature instead of setpoint temperature leads to any significant improvement in the natural ventilation hours unless a more relaxed ATC band (IMAC 80) is chosen. The choice of the ATC band and the percentage of occupancy hours that can lie outside that band, can significantly impact the space cooling energy consumption. 
The weighting coefficient described in equation 2 increases with the indoor air velocity. As air velocity increases, the effect $T_{m r t}$ on $T_{o}$ reduces and $T_{o}$ tends to reach $T_{a}$. During the air-conditioning period, increasing air velocities and subsequently air temperatures result in acceptable indoor operative temperatures at increased air temperatures. This allows for using increased cooling setpoint temperatures, subsequently minimising the cooling energy consumption. During the natural ventilation period, air temperatures are typically higher; therefore, increased air velocities are usually preferred to compensate for higher air temperatures. However, because the ATC models already assume behavioural adaptations, including air speed, they do not explicitly account for changes in $T_{n}$ for increasing air velocity. Whereas CEN Standard 15251 and ASHRAE 55 standard provides for increasing $T_{o}$ at elevated air speeds as per ATC and 'predicted mean vote - prected percentage dissatisfied' comfort models, as per IMAC, it is unclear whether and to what extent such an increase in $T_{o}$ with elevated air speed can be allowed [75,118]. This needs to be further examined.

Considering the limitations in modelling IMMBs, it is necessary to develop a standardised BPS modelling protocol for them. Such a protocol includes appropriate $h_{r}$ and $h_{c}$ values, operating conditions, such as the choice of thermal comfort model and band, incorporation of micro-climatic effects, and accounting for internal thermal mass . This is important for the successful design of mixed-mode buildings for claiming energy or green building ratings based on BPS, and for performance predictions to minimise the gap between predicted and actual performances [119].

\section{Conclusions}

The potential of mixed-mode buildings in India is analysed in this study. It is found to be low in general, i.e., the possibility for natural ventilation is less than $10 \%$ of the occupancy hours. 
The importance of the cooling setpoint temperature and design parameters in reducing energy consumption are reiterated in this study in the context of IMMBs. A few passive strategies, such as minimising the external and internal heat gains, are crucial for both fully airconditioned and fully naturally ventilated buildings. Nevertheless, the study indicates that energy-efficient fully air-conditioned buildings, however efficient, are not necessarily efficient mixed-mode buildings by default. Given the building construction practices in India, the growth in the air-conditioning market, and the slow pace of ECBC implementation, in the short term, policy initiatives must focus on simple, specific, and effective measures for minimising space cooling energy consumption in buildings, such as effective shading and optimum WWR. Furthermore, policies should advocate for the use of moderately high cooling setpoint temperatures. This is especially important for buildings that fall outside the purview of the ECBC. In the medium term, further research should be conducted considering detailed and realistic operating parameters and schedules to determine the optimum building envelope and internal conditions for IMMBs. This would reduce energy consumption during the air-conditioned mode and increase the natural ventilation hours while maintaining thermal comfort conditions.

\section{Declaration of interest}

None

\section{Funding acknowledgment}

This research did not receive any specific grant from any public, commercial, or non-profit funding agencies.

\section{Acknowledgment}

A special thank you is owed to Dr. Stefan Thomas (Director, FG POL, Wuppertal Institut) for 
providing valuable feedback, guidance, and constant support throughout the research process.

\section{References}

[1] CSO, Energy Statistics 2017, Central Statistics Office, New Delhi, 2017. http://www.mospi.nic.in/sites/default/files/publication_reports/Energy_Statistics_2017 r.pdf.pdf.

[2] Planning Commission, The Final Report of the Expert Group on Low Carbon Strategies for Inclusive growth, New Delhi, 2014.

[3] Y. Bhargava, India has second fastest growing services sector, The Hindu. (2014). https://www.thehindu.com/business/budget/india-has-second-fastest-growing-servicessector/article6193500.ece (accessed August 2, 2018).

[4] N. Abhyankar, N. Shah, W.Y. Park, A. Phadke, Accelerating Energy Efficiency Improvements in Room Air Conditioners in India: Potential, Costs-Benefits, and Policies, Ernest Orlando Lawrence Berkely National Laboratory, 2017. http://etapublications.lbl.gov/sites/default/files/lbnl-1005798.pdf.

[5] BEE, Bureau of Energy Efficiency, (2013). https://www.beestarlabel.com/\# (accessed June 8, 2018).

[6] A.F. Pales, K. West, CHP/DC Country Scorecard: India, 2014. https://www.iea.org/publications/insights/insightpublications/IEA_CHP_IndiaScorecar d.pdf.

[7] A.N. Sharan, Project Details: State-wisse and application-wise field projects supported under UNDP-GEF CSH Project, UNDP-GEF Project on CSH, MNRE, Government of Inida \& TERI Press. 4 (2017) 31.

[8] S.C. Vedala, R.V. Bilolikar, P.K. Parnandi, R. Khosla, A. Jaiswal, D. Goldstein, B. Deol, Accelerating Energy Efficiency in India's Buildings Market, 2012.

[9] S. Yu, M. Evans, A. Delgado, Building Energy Efficiency in India: Compliance Evaluation of Energy Conservation Building Code, 2014. doi:10.2172/1128633.

[10] A.M. Dave, Lok Sabha starred question No. *277 to be answered on 21.03.2017: Paris Agreement, (2017).

http://164.100.47.194/Loksabha/Questions/QResult15.aspx?qref=49310\&lsno=16 (accessed April 7, 2018).

[11] AEEE, ECBC_report.pdf, AEEE, NITI Aayog, BEE, UNDF-GEF, 2017. http://indiaenergy.gov.in/wp-content/uploads/2017/10/ECBC_report.pdf (accessed June 15, 2018).

[12] BEE, Energy Conservation Building Code 2017, Bureau of Energy Efficiency, New Delhi, 2017.

[13] F. Alamdari, D. Arnold, W. Bordass, K. Ho, R.J. Oughton, C. Twinn, Mixed Mode Ventilation Systems 2000, Chartered Institution of Building Services Engineers, London, 2000.

[14] P. Heiselberg, Principles of hybrid ventilation, Hybrid Ventilation Centre, Aalborg University, 2002. http://www.hybvent.civil.aau.dk/puplications/report/Principles\%20of\%20H\%20V.pdf.

[15] G. Brager, S. Borgeson, Y. Lee, Summary report: Control strategies for mixed mode buildings, Centre for the Built Environment, UC Berkeley, 2007.

[16] P.A. Torcellini, M. Deru, B. Griffith, N. Long, S. Pless, R. Judkoff, D.B. Crawley, Lessons learned from field evaluations of six high-performance buildings, in: Pacific Grove, 2004. https://www.nrel.gov/docs/fy04osti/36290.pdf. 
[17] G.S. Brager, L. Baker, Occupant satisfaction in mixed-mode buildings, Building Research \& Information. 37 (2009) 369-380.

[18] M.P. Deuble, R.J. de Dear, Mixed-mode buildings: A double standard in occupants' comfort expectations, Building and Environment. 54 (2012) 53-60. doi:10.1016/j.buildenv.2012.01.021.

[19] A. Honnekeri, G. Brager, S. Dhaka, J. Mathur, Comfort and adaptation in mixed-mode buildings in a hot-dry climate, (2014) 0-13. doi:10.1016/j.enbuild.2013.06.009.Keywords.

[20] J.C. Salcido, A.A. Raheem, R.R.A. Issa, From simulation to monitoring: Evaluating the potential of mixed-mode ventilation (MMV) systems for integrating natural ventilation in office buildings through a comprehensive literature review, Energy and Buildings. 127 (2016) 1008-1018. doi:10.1016/j.enbuild.2016.06.054.

[21] N.K. Bansal, G. Hauser, G. Minke, Passive Building Design: A Handbook of Natural Climatic Control, Elsevier Science B.V., 1994.

[22] B. Givoni, Man, Climate and Architecture, Applied Science Publ., 1976.

[23] M. Santamouris, ed., Advances in passive cooling, London ; Sterling, VA : Earthscan, 2007. https://trove.nla.gov.au/version/34731353 (accessed June 14, 2018).

[24] S. Ezzeldin, S.J. Rees, The potential for office buildings with mixed-mode ventilation and low energy cooling systems in arid climates, Energy and Buildings. 65 (2013) 368-381. doi:10.1016/j.enbuild.2013.06.004.

[25] O.-H. Kwon, M.-H. Kim, A.-S. Choi, J.-W. Jeong, Energy saving potential of a hybrid ventilation system integrated with heat storage material, Energy and Buildings. 57 (2013) 346-353. doi:10.1016/j.enbuild.2012.11.008.

[26] L. Guan, M. Bennett, J. Bell, Development of a climate assessment tool for hybrid air conditioner, Building and Environment. 82 (2014) 371-380. doi:10.1016/j.buildenv.2014.09.002.

[27] M. Simonetti, V. Gentile, L. Liggieri, G.V. Fracastoro, M.G. Carrabba, Experimental analysis of "NAC-wall" for hybrid ventilation mode, Energy and Buildings. 152 (2017) 399-408. doi:10.1016/j.enbuild.2017.07.047.

[28] M. Fiorentini, J. Wall, Z. Ma, J.H. Braslavsky, P. Cooper, Hybrid model predictive control of a residential HVAC system with on-site thermal energy generation and storage, Applied Energy. 187 (2017) 465-479. doi:10.1016/j.apenergy.2016.11.041.

[29] R. Jagpal, Control Strategies for Hybrid Ventilation in New and Retrofitted Office and Education Buildings (HYBVENT), International Energy Agency, Hertfordshire, UK, 2006. http://www.iea-ebc.org/Data/publications/EBC_Annex_35_tsr.pdf (accessed June 14, 2018).

[30] E. McConahey, Finding the Right Mix Mixed Mode Ventilation, (2008) 36-48.

[31] A. Chunekar, S. Varshney, S. Dixit, Residential Electricity Consumption in India: What do we know?, Prayas (Energy Group), Pune, 2016.

[32] GRIHA, Case Studies, (n.d.). $\mathrm{http}: / /$ www.grihaindia.org/index.php?option=com_fabrik\&view=list\&listid=3\&t=libra ry (accessed July 7, 2018).

[33] S. Manu, Y. Shukla, R. Rawal, L.E. Thomas, R.D. Dear, Field studies of thermal comfort across multiple climate zones for the subcontinent: India Model for Adaptive Comfort ( IMAC ), Building and Environment. 98 (2016) 55-70. doi:10.1016/j.buildenv.2015.12.019.

[34] A. Phadke, N. Abhyankar, N. Shah, Avoiding 100 New Power Plants by Increasing Efficiency of Room Air Conditioners in India : Opportunities and Challenges, in: EEDAL '13, 2013: pp. 1-14. 
[35] ISHRAE, Air Conditioner Market in India, (n.d.). http://ishrae.in/newsdetails/AirConditioner-Market-in-India/338 (accessed June 8, 2018).

[36] V. Gupta, Natural cooling systems of Jaisalmer, Architectural Science Review. (1985) 58-64.

[37] B. Ford, N. Patel, P. Zaveri, M. Hewitt, Cooling without air conditioning: The Torrent Research Centre, Ahmedabad, India, Renewable Energy. 15 (1998) 177-182. doi:10.1016/S0960-1481(98)00150-5.

[38] M. Majumdar, Energy-efficient Buildings in India, The Energy and Resources Institute (TERI), 2001.

[39] D. Wentz, Office building in India, Holcim Foundation, Zurich, 2008.

[40] M. Doctor-pingel, R. Rawal, A. Baklina, V. Krishnaraj, P. Bourdon, Evaluating the Performance of Naturally Ventilated Brick and Lime Domes and Vaults in Warmhumid Climate in South India, in: PLEA 2014, 2014: pp. 16-18.

[41] LBC, Laurie Baker Centre for Habitat Studies, (n.d.). http://www.lauriebakercentre.org/ (accessed June 14, 2018).

[42] AVBC, Auroville Building Centre (AVBC) $\mid$ Auroville, (n.d.). https://www.auroville.org/contents/1121 (accessed June 14, 2018).

[43] P. Zaveri, N. Patel, Traditional Values and Architectural Understanding, in: n.d. http://research.auroville.org/system/papers/attachments/000/000/458/original/Tradition al_Values_and_Architectural_Understanding_Parul_Zaveri_Nimish_Patel.pdf.

[44] V. Gupta, Indian Myths and Realities, Architecture+Design. (1992) 19-26.

[45] P. Kochar, The 'State of Play' of Sustainable Buildings in India, United Nations Environment Programme, 2010.

https://wedocs.unep.org/bitstream/handle/20.500.11822/8005/State\%20of\%20Play\%20for\%20Sustainable\%20Buildings\%20in\%20India2010994.pdf? sequence $=3$ \&isAllowed $=$ y.

[46] A. Tulsyan, S. Dhaka, J. Mathur, J.V. Yadav, Potential of energy savings through implementation of Energy Conservation Building Code in Jaipur city, India, Energy and Buildings. 58 (2013) 123-130. doi:10.1016/j.enbuild.2012.11.015.

[47] J.W. Axley, Application of Natura Ventilation for U.S. Commercial Buildings Climate suitability Design strategies and methods Modeling Studies, (2001).

[48] S. Borgeson, G. Brager, B. Coffey, P. Haves, Mixed-mode simulations for climate feasibility, Center for the Built Environment (CBE). (2009) 0-13.

[49] Y. Chen, Z. Tong, A. Malkawi, Investigating natural ventilation potentials across the globe: Regional and climatic variations, Building and Environment. 122 (2017) 386396.

[50] F.S. de la Flor, S.A. Domínguez, Modelling microclimate in urban environments and assessing its influence on the performance of surrounding buildings, Energy and Buildings. 36 (2004) 403-413. doi:10.1016/j.enbuild.2004.01.050.

[51] H. Wang, Q. Chen, A semi-empirical model for studying the impact of thermal mass and cost-return analysis on mixed-mode ventilation in office buildings, Energy and Buildings. 67 (2013) 267-274. doi:10.1016/j.enbuild.2013.08.025.

[52] T.L. Hemsath, K. Alagheband Bandhosseini, Sensitivity analysis evaluating basic building geometry's effect on energy use, Renewable Energy. 76 (2015) 526-538. doi:10.1016/j.renene.2014.11.044.

[53] L. Zhang, L. Zhang, Y. Wang, Shape optimization of free-form buildings based on solar radiation gain and space efficiency using a multi-objective genetic algorithm in the severe cold zones of China, Solar Energy. 132 (2016) 38-50. doi:10.1016/j.solener.2016.02.053. 
[54] N. Aste, F. Leonforte, M. Manfren, M. Mazzon, Thermal inertia and energy efficiency - Parametric simulation assessment on a calibrated case study, Applied Energy. 145 (2015) 111-123. doi:10.1016/j.apenergy.2015.01.084.

[55] X.-Y. Ma, Y. Peng, F.-Y. Zhao, C.-W. Liu, S.-J. Mei, Full Numerical Investigations on the Wind Driven Natural Ventilation: Cross Ventilation and Single-sided Ventilation, Procedia Engineering. 205 (2017) 3797-3803. doi:10.1016/j.proeng.2017.10.128.

[56] A. Brambilla, J. Bonvin, F. Flourentzou, T. Jusselme, On the Influence of Thermal Mass and Natural Ventilation on Overheating Risk in Offices, Buildings. 8 (2018) 47. doi:10.3390/buildings8040047.

[57] N. Groenhout, L. Partridge, Optimisation of Passive Ventilation Design for Public Assembly Buildings in a Tropical Climate, ECOLIBRIUM. (2010).

[58] P. Karava, A.K. Athienitis, T. Stathopoulos, E. Mouriki, Experimental study of the thermal performance of a large institutional building with mixed-mode cooling and hybrid ventilation, Building and Environment. 57 (2012) 313-326.

doi:10.1016/j.buildenv.2012.06.003.

[59] P. Raftery, E. Lee, T. Webster, T. Hoyt, F. Bauman, Effects of furniture and contents on peak cooling load, Energy and Buildings. 85 (2014) 445-457. doi:10.1016/j.enbuild.2014.09.081.

[60] N. Artmann, H. Manz, P. Heiselberg, Parameter study on performance of building cooling by night-time ventilation, Renewable Energy. 33 (2008) 2589-2598. doi:10.1016/j.renene.2008.02.025.

[61] S.D. Borgeson, Assessment of Energy Use and Comfort in Buildings Utilizing MixedMode Controls with Radiant Cooling, (2010). https://escholarship.org/uc/item/7c8347dk.

[62] J. Hu, P. Karava, Model predictive control strategies for buildings with mixed-mode cooling, Building and Environment. 71 (2014) 233-244. doi:10.1016/j.buildenv.2013.09.005.

[63] Y. Chen, L.K. Norford, H.W. Samuelson, A. Malkawi, Optimal control of HVAC and window systems for natural ventilation through reinforcement learning, Energy and Buildings. 169 (2018) 195-205. doi:10.1016/j.enbuild.2018.03.051.

[64] S. Dhaka, J. Mathur, V. Garg, V. Jain, EFFECT OF ENVELOPE PROPERTIES AND THERMAL ADAPTATION ON ENERGY CONSUMPTION AND COMFORT CONDITIONS THROUGH simulation of various ECMs, in: 12th Conference of International Building Performance Simulation Association, 2011: pp. 14-16.

[65] L. Thomas, P.C. Thomas, Unravelling the mix - towards effective simulation, implementation and operation of mixed mode buildings, in: Adapting to Change: New Thinking on Comfort, 2010: pp. 9-11.

[66] M.S. de Wit, Uncertainty in Predictions of Thermal Comfort in Buildings, PhD Thesis. (2001) 215-215.

[67] G. Brager, P. Gandhi, S. Dutton, Mixed Mode Simulation Tools, 2014.

[68] L. Peeters, I. Beausoleil-Morrison, B. Griffith, A. Novoselac, Internal Convection Coefficients for Building Simulation, Proceedings of Building Simulation 2011: 12th Conference of International Building Performance Simulation Association, Sydney, 14-16 November. (2011) 2370-2377.

[69] I. Beausoleil-Morrison, Algorithm for calculating convection coefficients for internal building surfaces for the case of mixed flow in rooms, Energy and Buildings. 33 (2001) 351-361. doi:10.1016/S0378-7788(00)00117-1.

[70] C.J. Koinakis, Combined thermal and natural ventilation modeling for long-term energy assessment: Validation with experimental measurements, Energy and Buildings. 37 (2005) 311-323. doi:10.1016/j.enbuild.2004.06.022. 
[71] Z. Zhai, Q.Y. Chen, P. Haves, J.H. Klems, On approaches to couple energy simulation and computational fluid dynamics programs, Building and Environment. 37 (2002) 857-864. doi:10.1016/S0360-1323(02)00054-9.

[72] G.N. Walton, AIRNET: A Computer Program for Building Airflow Network Modeling, National Institute of Standards and Technology, 1989.

[73] M. Swami, S. Chandra, Procedures for calculating natural ventilation airflow rates in buildings, ASHRAE Final Report FSEC-CR-163-86, ASHRAE .... (1987).

http://scholar.google.com/scholar?hl=en\&btnG=Search\&q=intitle:Procedures + for $+\mathrm{Cal}$ culating+Natural+Ventilation+Airflow+Rates+in+Buildings $\# 0 \% 5$ Cnhttp://scholar.goo gle.com/scholar?hl=en\&btnG=Search\&q=intitle:Procedures + for + calculating + natural + ventilation+airflow.

[74] Z. (John) Zhai, M.-H. Johnson, M. Krarti, Assessment of natural and hybrid ventilation models in whole-building energy simulations, Energy and Buildings. 43 (2011) 22512261. doi:10.1016/j.enbuild.2011.06.026.

[75] ASHRAE, ANSI/ASHRAE Standard 55-2010: Thermal Environmental Conditions for Human Occupancy, Atlanta, 2010.

[76] G.N. Walton, Thermal Analysis Research Program Reference Manual, U.S. Department of Commerce, National Bureau of Standards, 1983.

[77] S.H. Ho, L. Rosario, M.M. Rahman, Thermal comfort enhancement by using a ceiling fan, Applied Thermal Engineering. 29 (2009) 1648-1656.

doi:10.1016/j.applthermaleng.2008.07.015.

[78] S. Manu, Y. Shukla, R. Rawal, L.E. Thomas, R. de Dear, M. Dave, M. Vakharia, Assessment of Air Velocity Preferences and Satisfaction for Naturally Ventilated Office Buildings in India, in: Ahmedabad, 2014: p. 8.

[79] F. Babich, M. Cook, D. Loveday, R. Rawal, Y. Shukla, Transient three-dimensional CFD modelling of ceiling fans, Building and Environment. 123 (2017) 37-49. doi:10.1016/j.buildenv.2017.06.039.

[80] S. Borgeson, G. Brager, Occupant Control of Windows: Accounting for Human Behavior in Building Simulation, Center for the Built Environment UC Berkeley-Peer Reviewed. (2008) 0-13.

[81] K. Ackerly, G. Brager, Occupant Response to Window Control Signaling Systems; Appendix C: Mixed-mode Signal Case Study Summary, CBE; Universtiy of California. (2011).

[82] V. Fabi, R.V. Andersen, S. Corgnati, B.W. Olesen, Occupants' window opening behaviour: A literature review of factors influencing occupant behaviour and models, Building and Environment. 58 (2012) 188-198. doi:10.1016/j.buildenv.2012.07.009.

[83] Z. Tong, Y. Chen, A. Malkawi, Z. Liu, R.B. Freeman, Energy saving potential of natural ventilation in China: The impact of ambient air pollution, Applied Energy. 179 (2016) 660-668. doi:10.1016/j.apenergy.2016.07.019.

[84] I.A. Raja, J.F. Nicol, K.J. McCartney, M.A. Humphreys, Thermal comfort: use of controls in naturally ventilated buildings, Energy and Buildings. 33 (2001) 235-244. doi:10.1016/S0378-7788(00)00087-6.

[85] F. Haldi, D. Robinson, Interactions with window openings by office occupants, Building and Environment. 44 (2009) 2378-2395. doi:10.1016/j.buildenv.2009.03.025.

[86] E. Hofer, The Uncertainty Analysis of Model Results: A Practical Guide, Springer, 2018.

[87] A. Saltelli, M. Ratto, T. Andres, F. Campolongo, J. Cariboni, D. Gatelli, M. Saisana, S. Tarantola, Global Sensitivity Analysis: The Primer, 1 edition, Wiley-Interscience, Chichester, England; Hoboken, NJ, 2008. 
[88] P. Kvols, A. Tind, H. Erreboe, P. Heiselberg, H. Brohus, A. Hesselholt, H. Rasmussen, E. Seinre, S. Thomas, Application of Sensitivity Analysis in Design of Sustainable Buildings Application of Sensitivity Analysis in Design of Sustainable Buildings, (2007).

[89] C.J. Hopfe, J.L.M. Hensen, Uncertainty analysis in building performance simulation for design support, Energy and Buildings. 43 (2011) 2798-2805. doi:10.1016/j.enbuild.2011.06.034.

[90] S. Burhenne, Monte Carlo Based Uncertainty and Sensitivity Analysis for Building Performance Simulation, (2013).

[91] X. Chen, H. Yang, T. Wang, Developing a robust assessment system for the passive design approach in the green building rating scheme of Hong Kong, Journal of Cleaner Production. 153 (2017) 176-194. doi:10.1016/j.jclepro.2017.03.191.

[92] A.-T. Nguyen, S. Reiter, A performance comparison of sensitivity analysis methods for building energy models, Building Simulation. 8 (2015) 651-664.

[93] K. Menberg, Y. Heo, R. Choudhary, Sensitivity analysis methods for building energy models : Comparing computational costs and extractable information, Energy \& Buildings. 133 (2016) 433-445. doi:10.1016/j.enbuild.2016.10.005.

[94] G. Calleja, A. Carrillo, F. Domínguez, J. Manuel, C. López, Y. Zhang, Uncertainties and sensitivity analysis in building energy simulation using macroparameters, Energy and Buildings. 67 (2013) 79-87. doi:10.1016/j.enbuild.2013.08.009.

[95] SimLAB, n.d. https://ec.europa.eu/jrc/en/samo/simlab.

[96] Y. Khare, M.-C. Rafael, Morris SU (Sampling Uniformity) code, 2014. https://abe.ufl.edu/faculty/carpena/software/SUMorris.shtml.

[97] J. Chitale, Y. Khare, R. Muñoz-Carpena, G.S. Dulikravich, C. Martinez, An Effective Parameter Screening Strategy for High Dimensional Models, (2017) V007T09A017. doi:10.1115/IMECE2017-71458.

[98] Y. Zhang, I. Korolija, Performing complex parametric simulations with jEPlus, in: Shanghai, China, 2010.

[99] Y. Zhang, I. Korolija, jEPlus-An EnergyPlus simulation manager for parametrics, n.d. http://www.jeplus.org/wiki/doku.php (accessed July 18, 2018).

[100] R Core Team, R: A language and environment for statistical computing, R Foundation for Statistical Computing, Vienna, Austria, 2014. https://www.r-project.org/.

[101] G. Pujol, B. Iooss, A. Janon, Global Sensitivity Analysis of Model Outputs, (2017). https://cran.r-project.org/web/packages/sensitivity/sensitivity.pdf (accessed July 18, 2018).

[102] N.K. Bansal, G. Minke, Climatic zones and rural housing in India: German-Indian cooperation in scientific research and technological development, Forschungszentrum Jülich GmbH, Zentralbibliothek. (1995) 297.

[103] BIS, National Building Code of India 2016, Bureau of Indian Standards, New Delhi, 2016.

[104] White Box Technologies, ISHRAE Weather Files, White Box Technologies. (2008). http://weather.whiteboxtechnologies.com/ISHRAE (accessed October 10, 2018).

[105] M. Nunez, T.R. Oke, The Energy Balance of an Urban Canyon, J. Appl. Meteor. 16 (1977) 11-19. doi:10.1175/1520-0450(1977)016<0011:TEBOAU>2.0.CO;2.

[106] K. Niachou, S. Hassid, M. Santamouris, I. Livada, Comparative monitoring of natural, hybrid and mechanical ventilation systems in urban canyons, Energy and Buildings. 37 (2005) 503-513. doi:10.1016/j.enbuild.2004.09.016.

[107] T. Foken, Micrometeorology, Springer-Verlag, Berlin Heidelberg, 2008. //www.springer.com/de/book/9783540746669 (accessed June 19, 2018). 
[108] W. Kuttler, The Urban Climate - Basic and Applied Aspects, in: Urban Ecology, Springer, Boston, MA, 2008: pp. 233-248. doi:10.1007/978-0-387-73412-5_13.

[109] B. De, M. Mukherjee, Optimizing Street Canyon Orientation for Rajarhat Newtown, Kolkata, India, Scientific Journal of Riga Technical University. Environmental and Climate Technologies. 21 (2017) 5-17. doi:10.1515/rtuect-2017-0012.

[110] ASHRAE, 2017 ASHRAE Handbook -- Fundamentals, Har/Cdr edition, ASHRAE, Atlanta, GA, 2017.

[111] Z. Tong, Y. Chen, A. Malkawi, Defining the Influence Region in neighborhood-scale CFD simulations for natural ventilation design, Applied Energy. 182 (2016) 625-633. doi:10.1016/j.apenergy.2016.08.098.

[112] Z. Tong, Y. Chen, A. Malkawi, Estimating natural ventilation potential for high-rise buildings considering boundary layer meteorology, Applied Energy. 193 (2017) 276286. doi:10.1016/j.apenergy.2017.02.041.

[113] G. Thomas, A.P. Sherin, S. Ansar, E.J. Zachariah, Analysis of Urban Heat Island in Kochi, India, Using a Modified Local Climate Zone Classification, Procedia Environmental Sciences. 21 (2014) 3-13. doi:10.1016/j.proenv.2014.09.002.

[114] TERI, Final Report on Urban Planning Characteristics to Mitigate Climate Change in Context of Urban Heat Island Effect, The Energy and Resources Institute, Bangalore, 2017.

[115] J.S. Sekhon, Multivariate and Propensity Score Matching Software with Automated Balance Optimization, Journal of Statistical Software. 42 (2011). doi:10.18637/jss.v042.i07.

[116] F. Sarrazin, F. Pianosi, T. Wagener, Global Sensitivity Analysis of environmental models: Convergence and validation, Environmental Modelling \& Software. 79 (2016) 135-152. doi:10.1016/j.envsoft.2016.02.005.

[117] J. Laustsen, ENERGY EFFICIENCY REQUIREMENTS IN BUILDING CODES , ENERGY EFFICIENCY POLICIES FOR NEW BUILDINGS, (2008).

[118] CEN, CEN - EN 15251 - Indoor environmental input parameters for design and assessment of energy performance of buildings addressing indoor air quality, thermal environment, lighting and acoustics | Engineering360, 2007. https://standards.globalspec.com/std/1110417/cen-en-15251 (accessed June 22, 2018).

[119] CSE, Green rated buildings found to be energy guzzlers, says CSE study, (2014). https://www.cseindia.org/green-rated-buildings-found-to-be-energy-guzzlers-says-csestudy-5534 (accessed June 17, 2018). 